\begin{tabular}{|c|l|}
\hline Title & Climbing fiber synapse elimination in cerebellar Purkinje cells \\
\hline Author(s) & Watanabe, Masahiko; Kano, Masanobu \\
\hline Citation & $\begin{array}{l}\text { European Journal of Neuroscience, 34(10), 1697-1710 } \\
\text { https:/doi.org/10.1111/.1460-9568.2011.07894.X }\end{array}$ \\
\hline Issue Date & 2011-11 \\
\hline Doc URL & http://hdl.handle.net/2115/50376 \\
\hline Rights & The definitive version is available at wileyonlinelibrary.com \\
\hline Type & article (author version) \\
\hline File Information & EJN34_10_1697-1710.pdf \\
\hline
\end{tabular}

Instructions for use 


\title{
Climbing Fiber Synapse Elimination in Cerebellar Purkinje
}

\section{Cells}

\author{
Masahiko Watanabe ${ }^{1}$ and Masanobu Kano ${ }^{2}$ \\ ${ }^{1}$ Department of Anatomy, Hokkaido University Graduate School of Medicine, Sapporo \\ 060-8638 Japan, and ${ }^{2}$ Department of Neurophysiology, Graduate School of Medicine, \\ The University of Tokyo, Tokyo 113-0033, Japan.
}

Abbreviated Title: Climbing fiber synapse elimination

55 Pages, 6 Figures, 0 Table

The number of words: Abstract, 250; Introduction, 491

Correspondence to: Masahiko Watanabe

Department of Anatomy, Hokkaido University Graduate School of Medicine, Sapporo 060-8638, Japan. TEL, +81-11-706-5032; FAX, +81-11-706-5031; e-mail, watamasa@med.hokudai.ac.jp

Correspondence to: Masanobu Kano

Department of Neurophysiology, Graduate School of Medicine, The University of Tokyo, Tokyo 113-0033, Japan. TEL, +81-3-5841-3538; FAX +81-3-5802-3315; e-mail, mkano-tky@m.u-tokyo.ac.jp 


\begin{abstract}
Innervation of Purkinje cells (PCs) by multiple climbing fibers (CFs) is refined into mono-innervation during the first three postnatal weeks of rodents' life. In this review article, we will integrate the current knowledge on developmental process and mechanisms of $\mathrm{CF}$ synapse elimination. In the "creeper" stage of $\mathrm{CF}$ innervation (postnatal day $0(\mathrm{P} 0) \sim$ ), CFs creep among PC somata to form transient synapses on immature dendrites. In the "pericellular nest" stage (P5 ), CFs densely surround and innervate PC somata. Then, $\mathrm{CF}$ innervation is displaced to the apical portion of PC somata in the "capuchon" stage (P9 ), and translocate to dendrites in the "dendritic" (P12 ) stage. Along with the developmental changes of $\mathrm{CF}$ wiring, functional and morphological distinctions become larger among CF inputs. PCs are initially innervated by $>5$ CFs with similar strengths $(\sim \mathrm{P} 3)$. Only a single $\mathrm{CF}$ is selectively strengthened during P3-P7 (functional differentiation), and undergoes dendritic translocation from P9 on (dendritic translocation). Following the functional differentiation, perisomatic CF synapses are eliminated non-selectively, which proceeds in two distinct phases. The early phase (P7-P11) is conducted independently of parallel fiber (PF)-PC synapse formation, while the late phase (P12-P17) critically depends on it. The P/Q-type voltage-dependent $\mathrm{Ca}^{2+}$ channel in PCs triggers selective strengthening of single $\mathrm{CF}$ inputs, promotes dendritic translocation of the strengthened CFs, and drives the early phase of CF synapse elimination. On the other hand, the late phase is mediated by mGluR1-Gaq-PLC $\beta 4-P K C \gamma$ signaling cascade in PCs driven at PF-PC synapses, whose structural connectivity is stabilized and maintained by the GluR $\delta 2-C b \ln 1$-neurexin system.
\end{abstract}




\section{Introduction}

In neural circuit formation, supernumerary synapses are formed transiently around birth. Then, important synapses are functionally strengthened, while unnecessary synapses are weakened and eventually eliminated. This process is known as "synapse elimination" or "synapse pruning", and is widely accepted as an important step to refine initial redundant circuitry into functionally mature one. The climbing fiber (CF) to Purkinje cell (PC) synapse in the cerebellum provides an excellent model to study the process of synapse elimination in the central nervous system (Crepel 1982; Lohof et al. 1996; Hashimoto and Kano 2005; Kano and Hashimoto 2009).

At two dendritic domains, PCs receive two kinds of excitatory inputs distinct in neuronal origin, wiring diagram, and synaptic strength (Palay and Chan-Palay 1974; Ito 1984). Parallel fibers (PFs) are bifurcated axons of cerebellar granule cells (GCs), and innervate spines on distal dendrites or spiny branchlets. Despite the formation of $10^{5}-10^{6}$ PF synapses in individual PCs, each PF only makes one or two synapses to a given PC (Napper and Harvey, 1988). The strength of individual PF inputs is also weak; the order of 50 simultaneously active GCs are required to generate an action potential, so called "simple spikes" (Palay and Chan-Palay 1974; Ito 1984; Barbour, 1993). In contrast, most PCs in adulthood are mono-innervated by single CFs, but each CF forms 250-300 synaptic contacts along proximal dendritic tree of the innervating PCs (Ito 1984). In addition, CF synapses express five times more AMPA receptors than PF synapses (Masugi-Tokita et al., 2007; Yamasaki et al., 2011). As a result, activation of CFs causes strong depolarization that generates characteristic "complex spikes" (Miyakawa et al., 1992; Eccles et al., 1966; Davie et al., 2008).

An earlier electrophysiological study on juvenile rats in vivo shows that 
stimulation to the inferior olive after P3 elicits CF-mediated responses in PCs (Crepel, 1971). In contrast to the all-or-none nature of CF responses in adulthood, the responses of juvenile PCs are graded in parallel with the increase of stimulus intensities (Crepel et al., 1976). This is the first evidence that PCs are innervated by multiple CFs in early postnatal development. Subsequent studies in vivo revealed that both the percentage of PCs with multiple CF innervation and the average number of CFs innervating individual PCs decrease with postnatal development until attaining the one-to-one relationship (Crepel et al., 1981; Mariani and Changeux, 1981). Reciprocal to the numerical decrease of innervating CFs, summed excitatory postsynaptic currents (EPSCs) elicited by stimulating multiply-innervating CFs increase with postnatal development (Bosman et al., 2008; Hashimoto and Kano, 2003, 2005; Ohtsuki and Hirano, 2008; Scelfo and Strata, 2005). These results indicate that CF mono-innervation is established through functional strengthening of CF inputs on one hand and elimination of surplus CFs on the other hand.

In this review, we first summarize developmental process of $\mathrm{CF}$ synapse formation and elimination. Then, we will summarize the current understanding on molecular and cellular mechanisms for $\mathrm{CF}$ synapse elimination and discuss possible future directions of the research.

\section{Morphological change in $\mathrm{CF}$ innervation during cerebellar development}

Ramón y Cajal (1911) classified the development of CFs into three successive stages, i.e., the "pericellular nest or nid" stage, "capuchon" stage, and "dendritic" stage. Later, $\mathrm{CF}$ projection in the cerebellar cortex was investigated prior to the pericellular nest 
stage (Mason and Gregory, 1984; Mason et al., 1990; Chedotal and Sotelo, 1993), and the initial stage was named the "creeper" stage by Chedotal and Sotelo (1993). We adopt P5 (the initiation of pericellular contact), P9 (the initiation of dendritic translocation), and P12 (the initiation of perisomatic CF synapse elimination and reciprocal increase of perisomatic basket cell synapses) as a hallmark of these stages in mice. These postnatal days in mice are generally consistent or retarded by a day or two as compared to studies in rats. Development of $\mathrm{CF}$ innervation also differs to some extents among cerebellar lobules and from PC to PC in single animals (Sugihara, 2005).

\section{1-1. Creeper stage ( $\mathrm{P} 0 \sim)$}

After reaching the cerebellum in the late embryonic period, CFs creep among multi-layered PC perikarya, and extend unbranched terminal arbors until reaching the border with the external granular layer (Mason et al., 1990; Chedotal and Sotelo, 1992; Morara et al, 2001). The creeper-type CFs form a few contacts on the smooth surface of immature dendritic processes. In mice at P3, CFs ascend along long dendritic processes and reach short apical dendritic processes; during the course, CFs form type 2 vesicular glutamate transporter (VGluT2)-positive terminal swellings around these dendritic processes (Fig. 1A). Each olivocerebellar axon produces about 100 creeper-type CFs, which projecet to a few separate terminals fields (each with $50-150 \mu \mathrm{m}$ wide and 400-1200 $\mu \mathrm{m}$ long) aligned in a narrow longitudinal microzone (Sugihara, 2005).

In the creeper stage, PCs first exhibit poorly elaborated bipolar shapes and called "simple-fusiform" cells (Armengol and Sotelo, 1991). Then, as new primary dendrites grow from the apical, lateral, and basal aspects of perikarya, PCs enter the “complex-fusiform" phase. This phase peaks by P1 in rats, and gradually ends by P6. 
The initial contacts between creeper-type CFs and fusiform PCs are poor in presynaptic and postsynaptic specializations, and disappear with the regression of immature dendrites (Armengol and Sotelo, 1991).

\section{1-2. Pericellular nest stage (P5 )}

In the pericellular nest stage, CFs surround the basal part of monolayered PC somata, and establish synaptic contacts with perisomatic protrusions and thorns (Sugihara, 2005) (Fig. 1B-D, 1L, 2A, 2B). Because of the extensive protrusions, PCs are in the phase of "stellate cells" (Armengol and Sotelo, 1991). Among 100 creeper-type CFs, around 10 develop into nest-type CFs (Sugihara, 2005). As each olivocerebellar axon produces, on average, 7 CFs in adulthood (Sugihara et al., 2001), CFs massively retract their terminal arbours from the creeper to the nest stage (early retraction), and the retraction further proceeds during or after the nest stage (late retraction) (Sugihara, 2005).

In rats at P5, the creeper-type, nest-type, and their transitional type of CFs are observed, representing the beginning of the pericellular nest stage (Sugihara, 2005). In mice at P5, most CF terminals are still associated with dendritic processes (arrows in Fig. 1B). However, CF terminals take up more perisomatic position than at P3; this is likely caused by the retraction of lateral and basal dendrites assosiated with CFs and also by the restriction of CF terminals to the basal portion of growing apical dendrites. At P5, some CF terminals form small clusters around PC somata (arrowheads in Fig. 1B), which can be taken as the intitation of pericellular nests in mice too. From P5 to P9, pericellular nests develop progressively (Fig. 1C, 1D, 2A, 2B). The density of the total perisomatic synapses peaks at P9 (Fig. 2F), when CF synapses constitute as much as 
$88 \%$ of the total perisomatic synapses (Hashimoto et al., 2009a; Ichikawa et al., submitted) (Fig. 2G). Thus, it is during the pericellular nest stage when CF branches display high synaptogenic activities targeting PC somata.

\section{1-3. Capuchon stage (P9 )}

The capuchon (meaning a cone-shaped ceremonial hat) stage is characterized by the displacement of $\mathrm{CF}$ plexus to the apical portion of PC somata. In mice, dendritic tranlocation of CFs starts at P9 (Fig. 1D, L) and becomes magnificent by P15 (Fig. 1F, N). Simultaneously, the major perisomatic synapses switch from CF synapse to basket cell synapse from P9 to P15 (Fig. 2G, H). During the switching period, particularly at P12 (Fig. 1E, 1M, 2C), typical feature of the capuchon stage is appreciated (Ichikawa et al., submitted). At P12, CF and basket cell synapses occupy $63 \%$ and $33 \%$ respectively of the total perisomatic synapses. It is also during the switching period that a fraction of basket cell synapses are formed on to somatic spines in addition to flat somatic surface (Fig. 2G, H) (Ichikawa et al., submitted). Furthermore, clusters of AMPA-type glutamate receptors and $\mathrm{GABA}_{\mathrm{A}}$ receptors are clustered under single basket cell terminals (Fig. 2H). These findings suggest that, as CFs displace to apical somatic portion and dendrites, not a few somatic spines initially innervated by CFs are succeeded by basket cell fibers for a while (BF-spine synapse in Fig. 2G), during which postsynaptic receptors are reorganized from glutamatergic to GABAergic under the coverage of basket cell terminals (Fig. 2H). Thus, the capuchon stage represents dynamic transition and reorganization in the site of $\mathrm{CF}$ innervation site (i.e., perisomatic to peridendritic), input source of perisomatic innervation ( $\mathrm{CF}$ to basket cell fiber), and postsynaptic receptor phenotype (glutamatergic to GABAergic). 


\section{1-4. Dendritic stage (P12 )}

In the dendritic stage, $\mathrm{CF}$ synapses progressively translocate to growing $\mathrm{PC}$ dendrites (Altman, 1972; Chedotal and Sotelo, 1992; Sugihara, 2005; Hashimoto et al., 2009a) (Fig. 1E-G). In this stage, perisomatic spines contacting to CFs virtually disappear (Fig. 1J), and the fraction of CF synapses in the total perisomatic PC synapses steeply drops to $6 \%$ at P15 and $<1 \%$ at P20 (Fig. 2G). Reciprocal to the loss of perisomatic $\mathrm{CF}$ synapses, the height of $\mathrm{CF}$ projection in the molecular layer increases strikingly (Fig. 1H). When the dendritic translocation is evaluated as the height of CF projection relative to the thickness of the molecular layer (37\% at $\mathrm{P} 9,60 \%$ at $\mathrm{P} 12,69 \%$ at $\mathrm{P} 15$, and $76 \%$ at $\mathrm{P} 20$ ), it is thus clear that the translocation of CFs follows the growth of the molecular layer, most likely, the growth of PC dendrites (Fig. 1I) (Hashimoto et al., 2009a). Considering further increase of this score in adulthood (84\%; Ichikawa et al., 2002), dendritic translocation of CFs can be taken as a protracted process in animal life. In this regard, it is important that dendritic translocation of CFs is an activity-dependent process, as the administration of tetrodotoxin or AMPA receptor blockers atrophies CF innervation in adult rats and mice (Bravin et al., 1999; Kakizawa et al., 2005; Cesa et al., 2007).

\section{Distinct phase from multiple- to mono-CF innervation}

In parallel with the developmentalons become larger among multiple $\mathrm{CF}$ inputs and then elimination of redundant CF synapses starts to occur. We propose four distinct phases in the process from multiple $\mathrm{CF}$ innervation to mono-innervation; 1) functional 
differentiation among multiple CF inputs, 2) dendritic translocation of single "winner" CFs, 3) early and 4) late phases of CF synapse elimination (Fig. 3).

\section{2-1. Functional differentiation among multiple CF inputs}

Changes in relative synaptic strengths of multiple CFs innervating the same PC have been systematically studied during postnatal development by recording CF-mediated EPSCs in PCs from cerebellar slices of mice aged P2 to P21 (Hashimoto and Kano, 2003). This study shows that more than 5 discrete CF-EPSCs with similar amplitudes are recorded in PCs until around P3 (Fig. 4A, upper). In the second postnatal week, however, multiple CF-EPSCs recorded from each PC are differentiated into one large CF-EPSC and a few small CF-EPSCs (Fig. 4A, lower). These results unequivocally indicate that synaptic strengths of multiply-innervating CFs are relatively uniform in the neonatal period, and a single $\mathrm{CF}$ is selectively strengthened subsequently (Bosman et al., 2008; Hashimoto and Kano, 2003, 2005). Quantitative analyses of the disparity among the amplitudes of multiple CF-EPSCs in individual PCs demonstrate that one $\mathrm{CF}$ is selectively strengthened among multiple $\mathrm{CFs}$ innervating the same $\mathrm{PC}$ from P3 to P7 (Fig. 4B) (Hashimoto and Kano, 2003). Transient rises of glutamate concentration in the synaptic cleft are significantly higher after stimulation of the strongest CF than weaker CFs (Hashimoto and Kano, 2003). This is thought to result from the fact that the probability of multivesicular release (i.e., more than one synaptic vesicles are released simultaneously to a given postsynaptic site from the corresponding presynaptic release site) is higher for the strongest CF than for the weaker CFs.

These electrophysiological data are consistent with morphological changes in innervation pattern during this postnatal period. CFs have many creeping terminals in 
the PC layer at P4, when their terminal swellings show no particular aggregation around PC somata (Sugihara, 2005). Then, from P4 to P7, CFs come to surround several specific PC somata with their terminal clusters (nest-type CFs) (Sugihara, 2005) (Fig. 1C, 2A). Pericellular nests are constructed by multiple CFs with different neuronal origins; some $\mathrm{CFs}$ reach target PCs as trunk fibers ascending in the granular layer, while others reach as collateral branches coming from trunk fibers that innervate neighboring PCs (Sugihara, 2005; Hashimoto et al., 2009a). Thus, pericellular nests represent the morphological basis of multiple CF innervation of PCs. Importantly, the extent of somatic coverage by respective CFs in a given pericellular nest is not even (Sugihara, 2005). To quantitatively assess the different occupancy among multiply-innervating CFs, we employed double labeling of CFs with anterograde tracer biotinylated dextran amine (BDA) injected into the inferior olive and with antibody against CF terminal marker type 2 vesicular glutamate transporter (VGluT2), and examined the composition and localization of perisomatic synapses formed by a main BDA/VGluT2-double labeled CF (yellow columns and circles in Fig. 1K-N) and other lesser CFs labeled for VGluT2 only (green columns and circles) (Hashimoto et al., 2009a). As a result, CF synapses formed by one predominant $\mathrm{CF}$ amount to about $60 \%$ of the total perisomatic $\mathrm{CF}$ synapses at P9 (Fig. 1K). Considering that individual PCs are innervated by, on the average, 3.5 CFs at P9 (Fig. 4C), each of lesser CFs is assumed to occupy $<20 \%$ of the total perisomatic $\mathrm{CF}$ synapses. Therefore, functional differentiation among multiply-innervating CFs accompanies morphological differentiation, and both progress while they are constructing pericellular nests (Fig. 3B).

\section{2-2. Dendritic translocation of single "winner" CFs}


As described above, the site of CF innervation shifts from the soma to dendrites in postnatal development. This phenomenon is known as "CF translocation" (Altman and Bayer, 1997). We then investigated the relationship between the selective strengthening of single CFs and CF translocation (Hashimoto et al., 2009a).

The location of synapses along the somatodendritic domains of PCs can be estimated electrophysiologically by analyzing the kinetics of quantal EPSCs (qEPSCs) arising from single synaptic vesicles in CF terminals. At P7-P8 when the selective strengthening of single $\mathrm{CFs}$ in each PC has just completed (Fig. 4B), there is no significant difference in the distribution of rise times from $10 \%$ to $90 \%$ of peak amplitude of qEPSCs between the strongest CF and weaker CFs (Fig. 4D). Since the distribution of qEPSC rise time is affected by the somatodendritic locations of CF terminals (Roth and Hausser, 2001), synapses formed by the strongest CF and weaker CFs are thought to be located at similar locations, namely, on the soma at P7-P8 (Fig. 3A, P7). At P9-P10, the incidence of qEPSCs with slow rise time was more frequent for the strongest $\mathrm{CF}$ than for weaker $\mathrm{CFs}$, suggesting the initiation of $\mathrm{CF}$ translocation (Fig. 3B, P9 ). The difference in the distribution of qEPSC rise times becomes much larger from P11 to P14 (Fig. 4E). While the incidence of qEPSCs with slow rise time become more frequent for the strongest $\mathrm{CF}$ with age, the rise time of qEPSCs for weaker CFs are almost unchanged from P9 to P14 (Fig. 4D, E). These electrophysiological data collectively suggest that: (1) synaptic competition among multiple CFs occurs on the soma before P7 (Fig. 3A, P3 and P7; Fig. 3B, P3 P7), (2) only the strongest ("winner") CF starts to translocate to dendrites at P9 and the translocation continues thereafter (Fig. 3A, P12; Fig. 3B, P9 ), and (3) synapses of weaker ("loser") CFs remain around the soma (Fig. 3A, $\sim$ P7 and $\sim$ P12). 
These notions were tested morphologically by discriminating synapses formed by a major BDA/VGluT2-double labeled CF from those by other weaker CFs labeled for VGluT2 only (Fig. 1L-N; Hashimoto et al., 2009a). At P7, in spite of the presence of immature stem dendrite in "stellate" PCs, CFs innervate the soma only (Fig. 1C). Dendritic innervation by a main single $\mathrm{CF}$ starts at $\mathrm{P}$ 9, but its innervation is still confined to the basal portion of shaft dendrites (Fig. 1D, L). At P12 and thereafter, the main CF further extends along growing PC dendrites, while leaving weaker CFs around the soma (Fig. 1E-G, M, N). These lines of electrophysiological and morphological evidence demonstrate that a single winner CF, which is selectively strengthened by P7, is only permitted to translocate to dendrites (Fig. 3A).

\section{2-3. Early and late phases of CF synapse elimination}

From P3 to P6 when functional differentiation among multiple CFs becomes larger, there is no significant reduction in the average number of CFs per PC (Fig. 4C; Hashimoto et al., 2009b). The value begins to decrease from P7 (Fig. 4C; Hashimoto et al., 2009b; Scelfo and Strata, 2005). Therefore, CF synapse elimination does not proceed in parallel with functional differentiation of multiple CFs; rather, it starts after the strengthening of single 'winner' CFs in individual PCs. During dendritic translocation, the strongest CF keeps its perisomatic synapses during the second postnatal week (Fig. 3A, $\sim \mathrm{P} 12$ ). This is also true for weaker $\mathrm{CFs}$, which remain to innervate the soma and the very basal part of dendrites (Fig. 1M). At P15, CF synapses formed by both the strongest and weaker CFs are massively eliminated from the soma, whereas dendritic innervation by the strongest CF further extends distally (Fig. 1G, N). Therefore, CF synapse elimination is achieved through non-selective pruning of 
perisomatic $\mathrm{CF}$ synapses in the second postnatal week, and single winner CFs can thereby establish monopolized innervation in the third week (Hashimoto et al., 2009a).

Earlier studies on spontaneous cerebellar mutant mice (Crepel and Mariani 1976; Mariani et al. 1977; Crepel et al. 1980; Mariani and Changeux 1980) and animal models with experimentally-induced "hypogranular" cerebella (Woodward et al. 1974; Crepel and Delhaye-Bouchaud 1979; Bravin et al. 1995; Sugihara et al. 2000) have revealed that intact GCs and normal formation of PF-PC synapses are prerequisite for CF synapse elimination. Moreover, Crepel et al. (1981) demonstrated that the elimination of surplus CFs consists of two distinct phases, the "early phase" up to around P8 and the "late phase" from around P9 to P17 in rats (Crepel et al. 1981). In animals with "hypogranular" cerebella, the late phase of CF synapse elimination is severely impaired, while the early phase proceeds normally. This indicates that the early phase of CF synapse elimination is independent of PF-PC synapse formation, whereas the late phase critically depends on it. However, since these classical animal models have severe abnormality and deformity in the cerebellar development and structure other than GC genesis and PF-PC synapse formation, there remains a possibility that $\mathrm{CF}$ synapse elimination might be influenced by such developmental defects.

The analysis of mutant mice deficient in glutamate receptor $\delta 2$ (GluR $\delta 2$ or GluD2) has unequivocally revealed the PF synapse formation-independent early phase of $\mathrm{CF}$ synapse elimination and the PF synapse formation-dependent late phase (Hashimoto et al. 2009b). GluR $\delta 2$ is richly expressed in PCs and its deletion causes impaired PF synapse formation leading to reduced PF-PC synapse number to about half of control mice (Kashiwabuchi et al. 1995; Kurihara et al. 1997). Nevertheless, GluR $\delta 2$ deletion does not significantly affect the histoarchitecture of the cerebellum and 
morphology of PCs, including dendritic branching and domains. In both

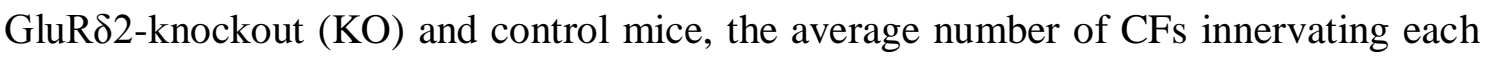
PC is similarly high at P5 and similarly reduced during P6-P11 (Fig. 4C). However, from P12 to P14, the average number of CFs becomes significantly larger in GluR $\delta 2$ KO mice than in control mice (Fig. 4C, Hashimoto et al. 2009b). These results collectively indicate that $\mathrm{CF}$ synapse elimination in mice can be classified into the early phase from P7 to around P11 (Fig. 3B, Early phase of CF elimination, P7 P11), which is independent of PF-PC synapse formation, and the late phase from around P12 (Fig. 3B, Late phase of $\mathrm{CF}$ elimination, P12 P17), which requires normal PF-PC synapse formation (Hashimoto et al. 2009b). As will be described next, the early and late phases of CF synapse elimination are controlled by distinct mechanisms (Fig. 5).

\section{Mechanisms for the early phase of CF synapse elimination}

$\mathrm{CF}$ activity, elevation of intracellular $\mathrm{Ca}^{2+}$ concentrations in $\mathrm{PCs}$, and activation of $\mathrm{Ca}^{2+}$-dependent intracellular signaling are considered to be the central mechanism for the early phase of CF synapse elimination (Fig. 5, top).

\section{3-1. CF activity}

Patterns of CF activity influence the early phase of CF synapse elimination. When normal activity pattern of CFs is altered by i.p. administration of harmaline to rats for 4 days from P9 to P12, multiple CF innervation persists in PCs at least until three months of age (Andjus et al., 2003). Moreover, genetic suppression of PC excitability by transgenic expression of a recombinant chloride channel during the early 
phase causes multiple $\mathrm{CF}$ innervation that persists to at least three months of age (Lorenzetto et al., 2009). Furthermore, Bosman et al. (2008) and Otsuki and Hirano (2008) have clarified that coincident activation of PC and CF during the early phase induces long-term potentiation (LTP) exclusively at synapses with strong CF inputs. This homosynaptic LTP require a strong postsynaptic $\mathrm{Ca}^{2+}$ signal thought to be mediated by voltage-dependent $\mathrm{Ca}^{2+}$ channels (VDCCs).

\section{3-2. P/Q-type voltage-dependent $\mathrm{Ca}^{2+}$ channel}

Hashimoto et al. (2011) have recently reported that P/Q-type VDCCs expressed in PCs drive the early phase of CF synapse elimination. Cav2.1 (or $\alpha 1 \mathrm{~A}$ ) is a pore-forming subunit of the P/Q-type VDCC, which is particularly abundant in PC dendrites, and constitutes the major $\mathrm{Ca}^{2+}$ current component in PCs (Mintz et al., 1992; Stea et al., 1994). In mice with PC-selective deletion of Cav2.1 (PC-Cav2.1 KO mice), the lack of $\mathrm{Ca}_{\mathrm{v}} 2.1$ mRNA expression or P/Q-type VDCC-mediated $\mathrm{Ca}^{2+}$ currents is confirmed in PCs at P2 or P5, respectively. At P4-P6, no significant difference is observed in the mean number of CFs innervating each PC between PC-Cav2.1 KO and control mice. Thereafter, PC-Cav2.1 KO mice manifest severe defects in CF synapse development and elimination. First, biased strengthening of single CF inputs from P5 to P7 in control mice (Fig. 4B, G) is severely impaired in PC-Cav2.1 KO mice (Fig. 4H), despite comparable 4-fold increase in summed amplitudes of multiple CF-EPSCs from P5 to P8 (Fig. 4F). Second, more than one CFs translocate to dendrites in PC-Cav2.1 $\mathrm{KO}$ mice. Third, CF synapse elimination is severely impaired in PC-Cav2.1 KO mice until around P12. Global Cav2.1 KO mice replicate the aforementioned phenotypes of PC-Cav2.1 KO mice, i.e., normal CF innervation at P4-P6, impaired biased 
strengthening of single $\mathrm{CF}$ inputs during the first postnatal week, and impaired subsequent elimination of surplus CFs until around P12. All these findings indicate an essential role of PC's P/Q-type VDCC in synaptic competition among multiple CFs and subsequent CF synapse elimination during the early phase (Fig. 5, top).

The physiological importance of the early phase of CF synapse elimination is appreciated well from chaotic excitatory wiring in PCs of global $\mathrm{Ca}_{\mathrm{v}} 2.1 \mathrm{KO}$ mice (Miyazaki et al., 2004) and PC-Cav2.1 KO mice (Miyazaki et al., submitted) (Fig. 6, right). Innervation territory by $\mathrm{CFs}$ is regressed proximally to the soma and basal part of shaft dendrites. As surplus CFs innervate the proximal somatodendritic compartment (gray $\mathrm{CF}$ in Fig. 6, right), we refer to this form of multiple $\mathrm{CF}$ innervation in $\mathrm{Ca}_{\mathrm{v}} 2.1 \mathrm{KO}$ mice as the "proximal type". Innervation mode and territory by PFs also change markedly. In control mice, PF terminals are small in size, oval in shape, and form synaptic contact with single PC spines in most cases. In global $\mathrm{Ca}_{\mathrm{v}} 2.1 \mathrm{KO}$ mice, however, a fraction of PF terminals are considerably enlarged and contact with multiple PC spines (arrowheads in Fig. 6; Miyazaki et al., 2004). These presynaptic phenotypes are reproduced in $\mathrm{PC}-\mathrm{Ca}_{\mathrm{v}} 2.1 \mathrm{KO}$ mice, but not in $\mathrm{GC}^{-C a} \mathrm{v}_{\mathrm{v}} 2.1 \mathrm{KO}$ mice (Miyazaki et al., submitted). This finding eventually highlights that $\mathrm{Ca}_{\mathrm{v}} 2 \cdot 1$-mediated $\mathrm{Ca}^{2+}$ signaling and dynamics in PCs retrogradely affect the size, shape, and contact number of PF terminals. Furthermore, PF territory expands reciprocally to proximal dendrites and somata, and covers the entire somatodendritic compartment in global $\mathrm{Ca}_{\mathrm{v}} 2.1 \mathrm{KO}$ and PC-Ca $2.1 \mathrm{KO}$ mice. As a result, characteristic features of excitatory synaptic wiring in wild-type PCs, i.e., segregated innervation territory by CFs and PFs and mono-innervation by single CFs (Fig. 6, middle), are completely disrupted in these mutant mice. Similar phenotypes are also induced after chronic blockades of neuronal activity by tetrodotoxin and AMPA 
receptors by NBQX in mature cerebellum (Bravin et al., 1999; Kakizawa et al., 2005; Cesa et al., 2007). Taken altogether, strong $\mathrm{CF}$ activities that induce $\mathrm{Ca}^{2+}$ influx through P/Q-type VDCCs give competitive advantage to single winner CFs, which expels an enormous number of PF inputs to distal dendrites and eliminates surplus CFs remaining on the PC soma. This molecular function thus strengthens the functional and innervations bases for a single strongest $\mathrm{CF}$, and propels the early phase of $\mathrm{CF}$ synapse elimination.

\section{3-3. Insulin-like growth factor and TrkB}

Insulin-like growth factor I (IGF-1) is also involved in CF synapse elimination from P8 to P12 (Kakizawa et al., 2003). IGF-1 is thought to enhance the strength of CF synapses and promote their survival, whereas the shortage of IGF-1 impairs the development of CF synapses (Kakizawa et al., 2003). In addition, Sherrard et al. (2009) reported that around the onset of the early phase of CF synapse elimination, the inferior olive and cerebellum decrease the expression of active, phosphorylated form of full-length TrkB, a receptor for brain-derived neurotrophic factor (BDNF), but increase the expression of the truncated form that acts as a negative regulator of TrkB signaling. This expression pattern is reproduced during $\mathrm{CF}$ degeneration following the pedunculotomy. This finding suggests that developmental decrease in TrkB signaling could be involved in the early phase of CF synapse elimination. The sites of synaptic expression and action by these growth factor and neurotrophin receptor remain largely elusive.

\section{Mechanisms for the late phase of CF synapse elimination}


Since normal PF-PC synapse formation is prerequisite for the late phase of CF synapse elimination, any molecules required for PF-PC synapse formation and maintenance contribute to the late phase. Among such molecules, GluR $\delta 2$ and Cbln 1 play unique roles in the formation and maintenance of PF-PC synapses, and in the construction of the structural basis for molecular mechanisms activated by PF synaptic inputs. The mGluR1-Gaq-PLC $\beta 4-\mathrm{PKC} \gamma$ signaling cascade in PCs is driven by neural activity through the mossy fiber-to-GC/PF-to-PC pathway, and plays a central role in eliminating surplus CF synapses remaining on the PC soma (Fig. 5, bottom).

\section{4-1 GluR $\delta 2$}

Although GluR $\delta 2$ is a member of 18 subunits of ionotropic glutamate receptors (Araki et al., 1993; Lomeli et al., 1993), it does not function as glutamate-gated ion channels (Hirai et al., 2005; Kakegawa et al., 2007a, 2008). Rather, GluR $\delta 2$ plays an important role in the formation and maintenance of the PF-PC synapse (Kashiwabuchi et al., 1995; Takeuchi et al., 2005) through its selective expression at this synapse, but not CF synapse (Takayama et al., 1995; Landsend et al., 1997), and also through specific interaction of its $N$-terminal domain with presynaptic neurexin via Cbln1 (Hirai et al., 2005; Matsuda et al., 2010; Uemura et al., 2010). Primary defects in GluR $\delta 2$ KO mice or spontaneous GluR $\delta 2$ mutant hotfoot mice occur in the connectivity of PF-PC synapses, as manifested by the emergence of free spines and the mismatching of preand postsynaptic specializations (Guastavino et al., 1990; Kurihara et al., 1997; Lalouette et al., 2001). Free spines are numerous in the distal dendritic domain innervated by PFs only (56\% of the total spines; green region in Fig. 6, left) and also found in the intermediate domain receiving mixed PF and CF innervation (37\%; light 
blue), whereas no free spines are found in the proximal domain innervated by CFs only (purple) (Ichikawa et al., 2002). This indicates that free spines are generated by failed synaptic contact with PF terminals. In PCs of wild-type mice, the density of synaptic AMPA receptors is approximately 5 times lower at PF synapse than at CF synapse, but this biased synaptic expression is disrupted by 3-to-5-fold increase of synaptic AMPA receptors at PF synapse in GluR $\delta 2 \mathrm{KO}$ mice (Yamasaki et al., 2011). Therefore, GluR $\delta 2$ potently strengthens structural connectivity of PF-PC synapses, while it weakens functional strength of the same synapses by reducing postsynaptic AMPA receptor number.

Defects in PF-PC synapse formation and stabilization also severely alter CF innervation in GluR $\delta 2 \mathrm{KO}$ mice. Distal extension of CF territory is demonstrated by increased CF distribution in the molecular layer of GluR $\delta 2 \mathrm{KO}$ mice (up to $95 \%$ of the molecular layer) compared to control mice (84\%) (Ichikawa et al., 2002). This is caused by extension of CFs along and beyond dendritic trees of a given PCs to take over free spines on distal dendrites. Such an aberrant extension eventually produces a number of ectopic CF synapses targeting distal dendrites, and causes a "distal type" of multiple CF innervation (gray CF in Fig. 6, left). This morphological observation is consistent with $\mathrm{Ca}^{2+}$ imaging combined with electrophysiological recording. In GluR $\delta 2 \mathrm{KO}$ mice, a single strong CF elicits large EPSCs with fast rise time and high $\mathrm{Ca}^{2+}$ elevation spreading throughout the dendritic tree, whereas weak CFs elicit small EPSCs with slow rise time and low $\mathrm{Ca}^{2+}$ elevation confined to local distal dendrites (Hashimoto et al., 2001). These unique phenotypes in GluR $\delta 2 \mathrm{KO}$ mice indicate that PFs compete for the innervation territory with CFs during development. In this heterosynaptic type of competition, GluR $\delta 2$ selectively strengthens PF synapses at distal dendrites, and 
restricts $\mathrm{CF}$ innervation to proximal dendrites. This heterosynaptic mechanism for $\mathrm{CF}$ territory restriction plays an essential role in the establishment of $\mathrm{CF}$ mono-innervation in the late phase by rather non-selective elimination of CF synapses remaining on the PC soma.

According to a recent report by Kaneko et al. (2011), the arborization of PC dendrites undergoes dynamic remodeling from multiplaner to monoplaner configuration during the third and fourth postnatal weeks in mice (Kaneko et al., 2011). They also report that distal portions of minor dendritic arbors of multiplanar PCs are often associated with collaterals of main $\mathrm{CF}$ branches, suggesting that distal type of CF innervation occurs frequently during normal cerebellar development. However, small CF-EPSCs with slow rise times, which reflect the distal type of CF innervation, are rarely recorded in wild-type PCs (Hashimoto et al., 2001). Therefore, it is uncertain whether the CF collaterals can form functional synapses on minor dendritic arbors of multiplanar PCs in normal development.

\section{4-2 Cbln1}

Cbln1 was originally identified as a precursor of PC-specific peptide cerebellin, thus being originally termed precerebellin (Slemmon et al., 1984). However, C-terminal two-thirds of Cbln1 share significant structural similarity to the globular domain of complement C1q chain (Urade et al., 1991; Kishore \& Reid, 2000). Cbln1 is highly expressed in cerebellar GCs, released to the extracellular space, and highly accumulated in the synaptic cleft of PF-PC synapses (Bao et al., 2005; Hirai et al., 2005; Miura et al., 2009).

Cooperative role of Cbln1 and GluR $\delta 2$ was first indicated by similar cerebellar 
phenotypes between Cbln1 KO and GluR $\delta 2$ KO mice, including free spines, mismatching of pre- and postsynaptic specialization at PF synapses, distal extension of CF territory, severe persistence of multiple CF innervation at distal dendrites, and impaired long-tem depression (Hirai et al., 2005) (Fig. 6, left). It is now widely known that Cbln1 is a unique bidirectional synaptic organizer. Cbln1 directly binds to the $N$-terminal domain of GluR $\delta 2$ and promotes clustering of postsynaptic molecules, while it also binds to presynaptic neurexins carrying the splice site 4 insert and induces presynaptic differentiation (Matsuda et al., 2010; Uemura et al., 2010; Matsuda and Yuzaki, 2011). Therefore, trans-synaptic interaction of postsynaptic GluR $\delta 2$ and presynaptic neurexins via Cbln1 mediates synaptic connectivity between PF terminals and PC spines. This molecular function provides a structural basis for mGluR1-Gaq-PLC $\beta 4-P K C \gamma$ signaling in PCs that is driven by PF synaptic activity and plays a central role for eliminating redundant CF synapses on the PC soma (see below). Importantly, the GluR82-Cbln1-neurexin system is also essential to maintain the PC circuitry in adulthood, as the characteristic phenotypes in GluR $\delta 2 \mathrm{KO}$ or Cbln1 $\mathrm{KO}$ mice are restored by rescue experiments (Ito-Ishida et al., 2008; Torashima et al., 2009), and are reproduced by molecular ablation in adulthood (Takeuchi et al., 2005; Miyazaki et al., 2010).

\section{4-3 mGluR1 signaling pathway}

During normal development, PCs richly express mGluR1 of the group I mGluR, $\mathrm{G}_{\alpha \mathrm{q}}$ of the heterotrimeric $\mathrm{Gq}$ family, type 3 and 4 isoforms of the phospholipase $\mathrm{C} \beta$ (PLC $\beta 3$ and PLC $\beta 4$ ), and the $\gamma$ subtype of the protein kinase $\mathrm{C}$ (PKC $\gamma$ ) (Saito et al., 1988; Shigemoto et al., 1992; Tanaka et al., 2000; Watanabe et al., 1998; Nakamura et 
al., 2004; Nomura et al., 2006). Multiple CF innervation persists into adulthood in null-mutant mice deficient in mGluR1, $\mathrm{G}_{\alpha \mathrm{q}}, \operatorname{PLC} \beta 4$, or PKC $\gamma$, whereas dendritic trees of PCs and PF synapse formation are normal in all these mice (Hashimoto et al., 2000; Ichise et al., 2000; Kano et al., 1995; Kano et al., 1997; Kano et al., 1998; Offermanns et al., 1997; Levenes et al., 1997). Electrophysiological examination demonstrates that the elimination of surplus CF synapses occurs normally during the first and early second postnatal weeks in the four mouse strains. However, these mice display abnormal synapse elimination toward the end of the second postnatal week. These results suggest that the signaling cascade from mGluR1 to PKC $\gamma$ is essential for the late phase of $\mathrm{CF}$ synapse elimination, but dispensable for the early phase of CF synapse elimination (Fig. 5, bottom). Importantly, the formation and function of PF-PC synapses are normal in these mutant mice. Therefore, impaired CF synapse elimination is not caused secondarily by the defect in PF synaptogenesis.

The defect of CF synapse elimination in mGluR1 KO mice is restored by selective transgenic expression of mGluR1a in PCs (Ichise et al., 2000). PC-specific expression of a PKC inhibitor peptide also impairs regression of CF synapses (De Zeeuw et al., 1998). Furthermore, intracerebellar localization of multiply-innervated PCs in PLC $\beta 4$ KO mice exactly matches with that of PCs predominantly expressing PLC $\beta 4$ in control mice (Kano et al., 1998). These lines of evidence further support that the mGluR1-to-PKC $\gamma$ signaling cascade in PCs, but not other cell types, plays a central role in the late phase of CF synapse elimination.

The mGluR1 signals required for the late phase of synapse elimination are thought to be driven by PF activity, since mGluR1 can readily be activated by PF inputs (Batchelor et al., 1994; Finch and Augustine, 1998; Takechi et al., 1998). Furthermore, 
chronic blockade of cerebellar NMDA receptors results in the impairment of CF synapse elimination (Rabacchi et al., 1992) specifically in its later phase (Kakizawa et al., 2000). NMDA receptors are not expressed at either PF or CF synapses in PCs at this age, but are abundantly expressed at mossy fiber-GC synapses (Kakizawa et al.,2000; Yamada et al., 2001). Therefore, chronic blockade of cerebellar NMDA receptors should affect mossy fiber to GC transmission. Although NMDA receptors are reported to be present in PCs during early development and in adulthood (Renzi et al., 2007; Piochon et al., 2007), they do not seem to contribute to CF synapse elimination. Taken together, neural activity along the mossy fiber-to-GC /PF-to-PC pathway and the subsequent activation of the mGluR1 signaling cascade in PCs are the key mechanism for the late phase of CF synapse elimination (Fig. 5, bottom) (Kakizawa et al., 2000).

\section{4-4 Other molecules}

Genetic or pharmacological deletion in mice of TrkB (Bosman et al., 2006; Johnson et al., 2007), myosin Va (Takagishi et al., 2007), glutamate transporter GLAST (Watase et al., 1998), or novel brain-specific receptor-like protein family BSRP (Miyazaki et al., 2006) also impairs CF synapse elimination in the second postnatal week. Numerous free spines as well as distal extension of CF territory is also reported in spontaneous ataxic mutant rigoletto (rig) (also known as waddles; wdl) (Hirasawa et al., 2007), which is caused by a 19 bp deletion in exon 8 of carbonic anhydrase Car8 gene (Jiao et al., 2005). However, it has not been examined whether CF synapse elimination is normal or not.

Null mutant mice deficient in $\mathrm{Ca}^{2+} /$ calmodulin-dependent protein kinase IV (CaMKIV) are reported to have persistent multiple CF innervations, but it is unclear at which stage of postnatal development the impairment occurs (Ribar et al., 2000). Null 
mutant mice deficient in $\alpha$-calcium/calmodulin-dependent protein kinase II ( $\alpha \mathrm{CaMKII})$ also display multiple CF innervations at P21-P28 (Hansel et al., 2006). Since this phenotype disappears in adulthood, $\alpha$ CaMKII deficiency delays, but not prevents, CF synapse elimination.

\section{Homosynaptic and heterosynaptic competitions}

The elucidation of molecular mechanisms involving the early and late phases of CF synapse elimination has substantiated that these mechanisms work in concert to promote homosynaptic competition among multiple CFs and heterosynaptic competition between PF and CF (Fig. 5). In early postnatal days, CFs from multiple neuronal origins converge on the soma of the same PCs, and their neural activities inducing P/Q-VDCC-mediated $\mathrm{Ca}^{2+}$ influx are the central mechanism for the early phase of $\mathrm{CF}$ synapse elimination. In the first postnatal week, $\mathrm{PC}-\mathrm{Ca}_{\mathrm{v}} 2.1 \mathrm{KO}$ mice are severely impaired in biased strengthening of single CF inputs (Fig. 4H), whereas they are normal in the mean number of CFs innervating each PC and in the summed amplitudes of multiple CF-EPSCs (Fig. 4F). Obviously, these results indicate that the enhancement of the total CF synaptic strengths and the biasing of individual synaptic strengths towards single selected inputs are based on different mechanisms. Although molecular bases for the mechanisms are currently unknown, it can be assumed that developmental change in the amount of resource necessary for maintaining synaptic efficacy and developmental competition for such resource by multiple inputs are two important factors (Sanes and Lichtmann, 1999; Goda and Davis, 2003). As the amount of resource increases with postnatal development, the total CF synaptic efficacy, as reflected in summed amplitudes of multiple CF-EPSCs (Fig. 4F), becomes larger. This process itself is 
independent of P/Q-type VDCCs, but activity-dependent assignment of the resource to respective CFs depends on P/Q-type VDCCs. Stronger CFs can activate postsynaptic P/Q-type VDCCs more effectively and may gain more resource than weaker CFs. This homosynaptic competition results in selective strengthening of a single "winner" CF that can translocate to dendrites, and in the weakening of the rest of CFs that remain in perisomatic sites. The promotion of dendritic translocation by the single "winner" $\mathrm{CF}$ will then fuel heterosynaptic competition with PF inputs for innervation territory on dendritic trees of PCs.

In the late phase of CF synapse elimination, $\mathrm{PC}$ dendrites grow dynamically and an enormous number of PF synapses come into existence (Woodward et al., 1971; Altman, 1972). Trans-synaptic interaction of the GluR $\delta 2-C b \ln 1$-neurexin system promotes the formation and maintenance of PF synapses on PC dendrites. The significance of this molecular function is two-fold (Fig. 5). First, complete occupancy of PC spines by PF synapses in distal dendrites eventually restricts $\mathrm{CF}$ innervation to proximal dendrites. This will provide a structural basis that fuels heterosynaptic competition with $\mathrm{CF}$ inputs for the innervation territory, which might in turn reduce the total amount of resource given to CF synapses. Second, owing to the establishment of PF-PC synapse formation, PF activity involving NMDA receptors at mossy fiber-GC synapses can activate the mGluR1-to-PKC $\gamma$ signaling cascade in PCs enough to produce certain signal promoting CF synapse elimination. Although molecular bases for the mGluR1-driven signal are currently unknown, the signal will provide a functional basis for non-selective elimination of perisomatic CF synapses in the late phase. Through the homo- and heterosynaptic competitions, PCs can establish both segregated innervation territory by CFs and PFs and CF mono-innervation. 


\section{Future directions}

The scheme in Fig. 5 further highlights important questions to be answered in future studies. How does the P/Q-type VDCC differentially assign the resource among CF synapses in an activity-dependent manner? How can the resource strengthen the strongest CF input, while it weakens lesser inputs? Likewise, how can mGluR1-driven signal conduct non-selective pruning of perisomatic CF synapses, while it spares dendritic CF synapses? Why are the dual mechanisms, i.e., the P/Q-type VDCC and mGluR1 signaling cascade, necessary to accomplish the developmental elimination of perisomatic CF synapses? What is the final event that executes the pruning of waning CF synapses? Above all, molecular identification of such resource and signal will be the most important issue to be clarified in future studies. Before closing this review, we will depict some of relevant findings that might help us solve these questions in future.

Chronic blockades of neuronal activities and AMPA receptors not only shift heterosynaptic competition to the disadvantage of single main CFs (Bravin et al., 1999; Kakizawa et al., 2005; Cesa et al., 2007), but also reduce glutamate concentration transient in the synaptic cleft and also the frequency of quantal EPSCs at CF-PC synapses (Kakizawa et al., 2005). This suggests that some retrograde signaling mechanisms exist to inform respective presynaptic terminals of the state of postsynaptic activities, and further weaken the synaptic basis of lesser inputs. CF activity leading to P/Q-type VDCC-mediated $\mathrm{Ca}^{2+}$ influx might link to the production of such retrograde signals. In young adult cerebellum, chronic blockade of mGluR1 or inositol 1,4,5-trisphosphate $\left(\mathrm{IP}_{3}\right)$ signaling in PCs is reported to decrease glutamate release probability from PFs (Furutani et al., 2006). BDNF is suggested to mediate the 
retrograde signaling for the maintenance of PF function (Furutani et al., 2006). Therefore, it would be interesting to test whether neurotrophins and cytokines mediate retrograde signaling for activity-dependent strengthening and maintenance of CF-PC synapses.

A steep decrease of perisomatic CF synapses occurs from P9 to P15 (Fig. 1J). The decrease accompanies reciprocal increase of basket cell synapses and the switching of receptor phenotypes in PC somata (Ichikawa et al., submitted) (Fig. 2G). The development of the powerful perisomatic inhibition could be related to differential actions of the mGluR1-driven signal between perisomatic and dendritic CF synapses. In this regard, the involvement of TrkB in the late phase of CF synapse elimination is interesting, because TrkB signaling is required for normal development of GABAergic innervation and transmission in PCs. In TrkB $\mathrm{KO}$ mice, the number of GABAergic synapses is reduced and the inhibitory postsynaptic currents are prolonged presumably due to impaired $\alpha 3$-to- $\alpha 1$ subunit switching (Bosman et al., 2006). It seems therefore important to test the role of perisomatic GABAergic synapse formation in non-selective pruning of perisomatic CF synapses.

It has been reported that waning CF synapses on PC somata and shaft dendrites are surrounded by ring-like structures with elevated lysosomal activity (Song et al., 2008). The structures are assumed to be Bergmann glia, and emerge abundantly in the cerebellar cortex during the second and third postnatal weeks. During synapse elimination of neuromuscular junction, similar structures in Schwann cells engulf bulb-shaped tips of retreating motor axons and their fragments "axosomes" (Bishop et al. 2004; Song et al. 2008). Therefore, it is possible that waning CF synapses might be tagged and recognized by nearby glia for final digestion in a manner similar to the 
retreating motor axons at neuromuscular junction. Interesting with this point, somatic spines initially innervated by CFs are not only taken over by basket cell fibers, but also surrounded by Bergmann glia (Ichikawa et al., submitted).

\section{Acknowledgment}

We thank Prof. Kouichi Hashimoto in Graduate School of Biomedical Sciences, Hiroshima University, Dr. Ryoichi Ichikawa in Sapporo Medical University School of Medicine, Dr. Taisuke Miyazaki and Dr. Miwako Yamasaki in Hokkaido University Graduate School of Medicine, Dr. Sho Kakizawa in Graduate School of Pharmaceutical Sciences, Kyoto University, Dr. Kazuo Kitamura and Dr. Hisako Nakayama in Graduate School of Medicine, University of Tokyo for their long-lasting contribution to our climbing fiber research and for critical reading of this review. This investigation was supported by Grants-in-Aid for Scientific Research 19100005 (M.W.) and 21220006 (M.K.), and the Strategic Research Program for Brain Sciences (Development of Biomarker Candidates for Social Behavior; M.K.) and the Global COE Program (Integrative Life Science Based on the Study of Biosignaling Mechanisms) from Ministry of Education, Culture, Sports, Science and Technology, Japan. 


\section{References}

Altman, J. (1972) Postnatal development of the cerebellar cortex in the rat. II. Phases in the maturation of Purkinje cells and of the molecular layer. J. Comp. Neurol., 145, $399-463$.

Altman. J. \& Bayer, S.A. (1997) Development of the cerebellar system: in relation to its evolution, structure, and functions. CRC Press, Boca Raton, FL.

Andjus, P.R., Zhu, L., Cesa, R., Carulli, D. \& Strata, P .(2003) A change in the pattern of activity affects the developmental regression of the Purkinje cell polyinnervation by climbing fibers in the rat cerebellum. Neuroscience, 121, 563-572.

Araki, K., Meguro, H., Kushiya, E., Takayama, C., Inoue, Y. \& Mishina, M. (1993) Selective expression of the glutamate receptor channel $\delta 2$ subunit in cerebellar Purkinje cells. Biochem. Biophys. Res. Commun., 197, 1267-1276.

Armengol, J.A. \& Sotelo, C. (1991) Early dendritic development of Purkinje cells in the rat cerebellum. A light and electron microscopic study using axonal tracing in 'in vitro' slices. Dev. Brain Res., 64, 95-114.

Bao, D., Pang, Z. \& Morgan, J.I. (2005) The structure and proteolytic processing of Cbln1 complexes. J. Neurochem., 95, 618-629.

Barbour, B. (1993). Synaptic currents evoked in Purkinje cells by stimulating individual 
granule cells. Neuron, 11, 759-769.

Batchelor, A.M., Madge, D.J. \& Garthwaite, J. (1994) Synaptic activation of metabotropic glutamate receptors in the parallel fibre-Purkinje cell pathway in rat cerebellar slices. Neuroscience, $\mathbf{6 3}, 911-915$.

Bishop, D.L., Misgeld, T., Walsh, M.K., Gan, W.B. \& Lichtman, J.W. (2004) Axon branch removal at developing synapses by axosome shedding. Neuron, 44, 651-661

Bosman, L.W., Hartmann, J., Barski, J.J., Lepier, A., Noll-Hussong, M., Reichardt, L.F. \& Konnerth, A. (2006) Requirement of TrkB for synapse elimination in developing cerebellar Purkinje cells. Brain Cell Biol., 35, 87-101.

Bosman, L.W., Takechi, H., Hartmann, J., Eilers, J. \& Konnerth, A. (2008) Homosynaptic long-term synaptic potentiation of the "winner" climbing fiber synapse in developing Purkinje cells. J. Neurosci., 28, 798-807.

Bravin, M., Morando, L., Vercelli, A., Rossi, F. \& Strata, P. (1999) Control of spine formation by electrical activity in the adult rat cerebellum. Proc. Natl. Acad. Sci. USA, 96, 1704-1709.

Bravin, M., Rossi, F. \& Strata, P. (1995) Different climbing fibres innervate separate dendritic regions of the same Purkinje cell in hypogranular cerebellum. J. Comp. Neurol., 357, 395-407. 
Cesa, R., Scelfo, B. \& Strata, P. (2007) Activity-dependent presynaptic and postsynaptic structural plasticity in the mature cerebellum. J. Neurosci., 27, 4603-4611.

Chedotal, A. \& Sotelo, C. (1992) Early development of the olivocerebellar projections in the fetal rat using CGRP-immunocytochemistry. Eur. J. Neurosci., 4, 1159-1179.

Chedotal, A. \& Sotelo, C. (1993) The 'creeper stage' in cerebellar climbing fiber synaptogenesis precedes the 'pericellular nest'--ultrastructural evidence with parvalbumin immunocytochemistry. Dev. Brain Res., 76, 207-220.

Crepel, F. (1971) Maturation of climbing fiber responses in the rat. Brain Res., 35, $272-276$.

Crepel, F. (1982) Regression of functional synapses in the immature mammalian cerebellunm. Trends Neurosci., 5, 266-269.

Crepel, F. \& Delhaye-Bouchaud, N. (1979) Distribution of climbing fibres on cerebellar Purkinje cells in X-irradiated rats. An electrophysiological study. J. Physiol., 290, 97-112.

Crepel, F., Delhaye-Bouchaud, N. \& Dupont, J.L. (1981) Fate of the multiple innervation of cerebellar Purkinje cells by climbing fibers in immature control, X-irradiated and hypothyroid rats. Brain Res., 227, 59-71. 
Crepel, F., Delhaye-Bouchaud, N., Guastavino, J.M. \& Sampaio, I. (1980) Multiple innervation of cerebellar Purkinje cells by climbing fibres in staggerer mutant mouse. Nature, 283,483-484.

Crepel, F. \& Mariani, J. (1976) Multiple innervation of Purkinje cells by climbing fibers in the cerebellum of the Weaver Mutant Mouse. J. Neurobiol., 7, 579-582.

Crepel, F., Mariani, J. \& Delhaye-Bouchaud, N. (1976) Evidence for a multiple innervation of Purkinje cells by climbing fibers in the immature rat cerebellum. $J$. Neurobiol., 7, 567-578.

Davie, J.T., Clark, B.A., Häusser, M. (2008) The origin of the complex spike in cerebellar Purkinje cells. J. Neurosci., 28, 7599-7609.

De Zeeuw, C.I., Hansel, C., Bian, F., Koekkoek, S.K., van Alphen, A.M., Linden, D.J. \& Oberdick, J. (1998) Expression of a protein kinase C inhibitor in Purkinje cells blocks cerebellar LTD and adaptation of the vestibulo-ocular reflex. Neuron, 20, 495-508.

Eccles, J.C., Llinas, R. \& Sasaki, K. (1966). The excitatory synaptic action of climbing fibres on the Purkinje cells of the cerebellum. J. Physiol., 182, 268-296.

Finch, E.A. \& Augustine, G.J. (1998) Local calcium signalling by inositol-1,4,5-trisphosphate in Purkinje cell dendrites. Nature, 396, 753-756. 
Furutani, K., Okubo, Y., Kakizawa, S., \& Iino, M. (2006) Postsynaptic inositol 1,4,5-trisphosphate signaling maintains presynaptic function of parallel fiber-Purkinje cell synapses via BDNF. Proc. Natl. Acad. Sci. USA, 103, 8528-8533.

Goda, Y. \& Davis, G.W. (2003) Mechanisms of synapse assembly and disassembly Neuron 40, 243-264.

Guastavino, J.M., Sotelo, C. \& Damez-Kinselle, I. (1990) Hot-foot murine mutation: behavioral effects and neuroanatomical alterations. Brain Res., 523, 199-210.

Hansel, C., de Jeu, M., Belmeguenai, A., Houtman, S.H., Buitendijk, G.H., Andreev, D., De Zeeuw, C.I. \& Elgersma, Y. (2006) $\alpha$ CaMKII Is essential for cerebellar LTD and motor learning. Neuron, 51, 835-843.

Hashimoto, K., Ichikawa, R., Kitamura, K., Watanabe, M. \& Kano, M. (2009a) Translocation of a "winner" climbing fiber to the Purkinje cell dendrite and subsequent elimination of "losers" from the soma in developing cerebellum. Neuron, 63, 106-118.

Hashimoto, K., Ichikawa, R., Takechi, H., Inoue ,Y., Aiba, A., Sakimura, K., Mishina, M., Hashikawa, T., Konnerth, A., Watanabe, M. \& Kano, M. (2001) Roles of glutamate receptor $\delta 2$ subunit (GluR $\delta 2)$ and metabotropic glutamate receptor subtype 1 (mGluR1) in climbing fiber synapse elimination during postnatal cerebellar development. $J$. Neurosci., 21, 9701-9712. 
Hashimoto, K. \& Kano, M. (2003) Functional differentiation of multiple climbing fiber inputs during synapse elimination in the developing cerebellum. Neuron, 38, 785-796.

Hashimoto, K. \& Kano, M. (2005) Postnatal development and synapse elimination of climbing fiber to Purkinje cell projection in the cerebellum. Neurosci. Res., 53, 221-228.

Hashimoto, K., Tsujita, M., Miyazaki, T., Kitamura, K., Yamazaki, M., Shin, H.S., Watanabe, M., Sakimura, K. \& Kano, M (2011) Postsynaptic P/Q-type $\mathrm{Ca}^{2+}$ channels in cerebellar Purkinje cells mediate synaptic competition among multiple climbing fiber inputs during postnatal development. Proc. Natl. Acad. Sci. USA. 108, 9987-9992.

Hashimoto, K., Watanabe, M., Kurihara, H., Offermanns, S., Jiang, H., Wu, Y., Jun, K., Shin, H.S., Inoue, Y., Wu, D., Simon, M.I. \& Kano, M. (2000) Climbing fiber synapse elimination during postnatal cerebellar development requires signal transduction involving Gaq and phospholipase C $\beta 4$. Prog. Brain Res., 124, 31-48.

Hashimoto, K., Yoshida, T., Sakimura, K., Mishina, M., Watanabe, M. \& Kano, M. (2009b) Influence of parallel fiber-Purkinje cell synapse formation on postnatal development of climbing fiber-Purkinje cell synapses in the cerebellum. Neuroscience, 162, 601-611.

Hirai, H., Pang, Z., Bao, D., Miyazaki, T., Li, L., Miura, E., Parris, J., Rong, Y., Watanabe, M., Yuzaki, M. \& Morgan, J.I. (2005) Cbln1 is essential for synaptic 
integrity and plasticity in the cerebellum. Nat. Neurosci., 8, 1534-1541.

Hirasawa, M., Xu, X., Trask, R.B., Maddatu, T.P., Johnson, B.A., Naggert, J.K., Nishina, P.M. \& Ikeda, A. (2007) Carbonic anhydrase related protein 8 mutation results in aberrant synaptic morphology and excitatory synaptic function in the cerebellum. Mol. Cell. Neurosci.. 35, 161-170.

Ichikawa, R., Miyazaki, T., Kano, M., Hashikawa, T., Tatsumi, H., Sakimura, K., Mishina, M., Inoue, Y. \& Watanabe, M. (2002) Distal extension of climbing fiber territory and multiple innervation caused by aberrant wiring to adjacent spiny branchlets in cerebellar Purkinje cells lacking glutamate receptor $\delta 2$. J. Neurosci., 22, 8487-8503.

Ichikawa, R., Yamasaki, M., Miyazaki, T., Konno, K., Hashimoto, K., Tatsum,i H., Inoue, Y., Kano, M. \& Watanabe, M. (2011) Developmental switching of perisomatic innervation from climbing fibers to basket cell fibers in cerebellar Purkinje cells. in submission.

Ichise, T., Kano, M., Hashimoto, K., Yanagihara, D., Nakao, K., Shigemoto, R., Katsuki, M. \& Aiba, A. (2000) mGluR1 in cerebellar Purkinje cells essential for long-term depression, synapse elimination, and motor coordination. Science, 288, 1832-1835.

Ito-Ishida, A., Miura, E., Emi, K., Matsuda, K., Iijima, T., Kondo, T., Kohda, K., Watanabe, M. \& Yuzaki, M. (2008) Cbln1 regulates rapid formation and maintenance of excitatory synapses in mature cerebellar Purkinje cells in vitro and in vivo. J. Neurosci., 
28, 5920-5930.

Ito, M. (1984) The CEREBELLUM and NEURAL CONTROL. Raven Press, New York.

Jiao, Y., Yan, J., Zhao, Y., Donahue, L.R., Beamer, W.G., Li, X., Roe, B.A., Ledoux, M.S. \& Gu, W. (2005) Carbonic anhydrase-related protein VIII deficiency is associated with a distinctive lifelong gait disorder in waddles mice. Genetics, 171, 1239-1246.

Johnson, E.M., Craig, E.T. \& Yeh, H.H. (2007) TrkB is necessary for pruning at the climbing fibre-Purkinje cell synapse in the developing murine cerebellum. J. Physiol., 582, 629-646.

Kakegawa, W., Kohda, K. \& Yuzaki, M. (2007a) The $\delta 2$ "ionotropic" glutamate receptor functions as a non-ionotropic receptor to control cerebellar synaptic plasticity. $J$. Physiol. (London), 584, 89-96.

Kakegawa, W., Miyazaki, T., Emi, K., Matsuda, K., Kohda, K., Motohashi, J., Mishina, M., Kawahara, S., Watanabe, M. \& Yuzaki, M. (2008) Differential regulation of synaptic plasticity and cerebellar motor learning by the C-terminal PDZ-binding motif of GluR82. J. Neurosci., 28,1460-1468.

Kakizawa, S., Miyazaki, T., Iino, M., Watanabe, M. \& Kano, M. (2005) Maintenance of presynaptic function by AMPA receptor-mediated excitatory postsynaptic activity in 
adult brain. Proc. Natl. Acad. Sci. USA, 102, 19180-19185.

Kakizawa, S., Yamada, K., Iino, M., Watanabe, M. \& Kano, M. (2003) Effects of insulin-like growth factor I on climbing fibre synapse elimination during cerebellar development. Eur. J. Neurosci., 17, 545-554.

Kakizawa, S., Yamasaki, M., Watanabe, M. \& Kano, M. (2000) Critical period for activity-dependent synapse elimination in developing cerebellum. J. Neurosci., 20, 4954-4961.

Kaneko, M., Yamaguchi, K., Eiraku, M., Sato, M., Takata, N., Kiyohara, Y., Mishina, M., Hirase, H., Hashikawa, T., Kengaku, M. (2011) .Remodeling of monoplanar Purkinje cell dendrites during cerebellar circuit formation. PLoS One. 6:e20108.

Kano, M. \& Hashimoto, K. (2009) Synapse elimination in the central nervous system. Curr. Opin. Neurobiol., 19, 154-161.

Kano, M., Hashimoto, K., Chen, C., Abeliovich, A., Aiba, A., Kurihara, H., Watanabe, M., Inoue, Y. \& Tonegawa, S. (1995) Impaired synapse elimination during cerebellar development in PKC $\gamma$ mutant mice. Cell, 83, 1223-1231.

Kano, M., Hashimoto, K., Kurihara, H., Watanabe, M., Inoue, Y., Aiba, A. \& TonegawaM S. (1997) Persistent multiple climbing fiber innervation of cerebellar Purkinje cells in mice lacking mGluR1. Neuron, 18, 71-79. 
Kano, M., Hashimoto, K., Watanabe, M., Kurihara, H., Offermanns, S., Jiang, H., Wu, Y., Jun, K., Shin, H.S., Inoue, Y., Simon, M.I. \& Wu, D. (1998) Phospholipase C $\beta 4$ is specifically involved in climbing fiber synapse elimination in the developing cerebellum. Proc. Natl. Acad. Sci. USA, 95, 15724-15729.

Kashiwabuchi, N., Ikeda, K., Araki, K., Hirano, T., Shibuki, K., Takayama, C., Inoue, Y., Kutsuwada, T., Yagi, T., Kang, Y., Aizawa, S., Mishina, M. (1995) Impairment of motor coordination, Purkinje cell synapse formation, and cerebellar long-term depression in GluR82 mutant mice. Cell, 81, 245-252.

Kishore, U. \& Reid, K.B. (2000) C1q: structure, function, and receptors. Immunopharmacology, 49, 159-170.

Kurihara, H., Hashimoto, K., Kano, M., Takayama, C., Sakimura, K., Mishina, M., Inoue, Y. \& Watanabe, M. (1997) Impaired parallel fiber-->Purkinje cell synapse stabilization during cerebellar development of mutant mice lacking the glutamate receptor $\delta 2$ subunit. J. Neurosci., 17, 9613-9623.

Lalouette, A., Lohof, A., Sotelo, C., Guenet, J. \& Mariani, J. (2001) Neurobiological effects of a null mutation depend on genetic context: comparison between two hotfoot alleles of the delta-2 ionotropic glutamate receptor. Neuroscience, 105, 443-455.

Landsend, A.S., Amiry-Moghaddam, M., Matsubara, A., Bergersen, L., Usami, S., 
Wenthold, R.J. \& Ottersen, O.P. (1997) Differential localization of $\delta$ glutamate receptors in the rat cerebellum: coexpression with AMPA receptors in parallel fiber-spine synapses and absence from climbing fiber-spine synapses. J. Neurosci., 17, 834-842.

Levenes, C., Daniel, H., Jaillard, D., Conquet, F. \& Crepel, F. (1997) Incomplete regression of multiple climbing fibre innervation of cerebellar Purkinje cells in mGluR1 mutant mice. Neuroreport 8, 571-574.

Lohof, A.M., Delhaye-Bouchaud, N. \& Mariani, J. (1996) Synapse elimination in the central nervous system: functional significance and cellular mechanisms. Rev. Neurosci., 7, 85-101.

Lomeli, H., Sprengel, R., Laurie, D.J., Kohr, G., Herb, A., Seeburg, P.H. \& Wisden, W. (1993) The rat delta-1 and delta-2 subunits extend the excitatory amino acid receptor family. FEBS, Lett., 315, 318-322.

Lorenzetto, E., Caselli, L., Feng, G., Yuan, W., Nerbonne, J.M., Sanes, J.R. \& Buffelli, M .(2009) Genetic perturbation of postsynaptic activity regulates synapse elimination in developing cerebellum. Proc. Natl. Acad. Sci. USA, 106, 16475-16480.

Mariani, J. \& Changeux, J.P. (1980) Multiple innervation of Purkinje cells by climbing fibers in the cerebellum of the adult staggerer mutant mouse. J. Neurobiol., 11, 41-50.

Mariani, J. \& Changeux, J.P. (1981) Ontogenesis of olivocerebellar relationships. I. 
Studies by intracellular recordings of the multiple innervation of Purkinje cells by climbing fibers in the developing rat cerebellum. J. Neurosci., 1, 696-702.

Mariani, J., Crepel, F., Mikoshiba, K., Changeux, J.P. \& Sotelo, C. (1977) Anatomical, physiological and biochemical studies of the cerebellum from Reeler mutant mouse. Philos. Trans. R. Soc. Lond. B Biol. Sci., 281, 1-28.

Mason, C.A., Christakos, S. \& Catalano, S.M. (1990) Early climbing fiber interactions with Purkinje cells in the postnatal mouse cerebellum. J. Comp. Neurol., 297, 77-90.

Mason, C.A. \& Gregory, E. (1984) Postnatal maturation of cerebellar mossy and climbing fibers: transient expression of dual features on single axons. J. Neurosci., 4, $1715-1735$.

Masugi-Tokita, M., Tarusawa, E., Watanabe, M., Molnar, E., Fujimoto, K. \& Shigemoto, R. (2007) Number and density of AMPA receptors in individual synapses in the rat cerebellum as revealed by SDS-digested freeze-fracture replica labeling. J. Neurosci., 27, 2135-2144.

Matsuda, K., Miura, E., Miyazaki, T., Kakegawa, W., Emi, K., Narumi, S., Fukazawa, Y., Ito-Ishida, A., Kondo, T., Shigemoto, R., Watanabe, M. \& Yuzaki, M. (2010) Cbln1 is a ligand for an orphan glutamate receptor $\delta 2$, a bidirectional synapse organizer. Science, 328, 363-368. 
Matsuda, K. \& Yuzaki, M. (2011) Cbln family proteins promote synapse formation by regulating distinct neurexin signaling pathways in various brain regions. Eur. J. Neurosci., 33, 1447-1461.

Mintz, I.M., Adams, M.E. \& Bean, B.P. (1992) P-type calcium channels in rat central and peripheral neurons. Neuron, 9, 85-95.

Miura, E., Matsuda, K., Morgan, J.I., Yuzaki, M. \& Watanabe, M. (2009) Cbln1 accumulates and colocalizes with Cbln 3 and GluR $\delta 2$ at parallel fiber-Purkinje cell synapses in the mouse cerebellum. Eur. J. Neurosci., 29, 693-706.

Miyakawa,, H., Lev-Ram, V., Lasser-Ross, N. \& Ross, W.N. (1992). Calcium transients evoked by climbing fiber and parallel fiber synaptic inputs in guinea pig cerebellar Purkinje neurons. J. Neurophysiol., 68, 1178-1189.

Miyazaki, T., Hashimoto, K., Shin, H.S., Kano, M. \& Watanabe, M. (2004) P/Q-type $\mathrm{Ca}^{2+}$ channel $\alpha 1 \mathrm{~A}$ regulates synaptic competition on developing cerebellar Purkinje cells. J. Neurosci., 24, 1734-1743.

Miyazaki, T., Hashimoto, K., Uda, A., Sakagami, H., Nakamura, Y., Saito, S.Y., Nishi, M., Kume, H., Tohgo, A., Kaneko, I., Kondo, H., Fukunaga, K., Kano, M,. Watanabe, M. \& Takeshima, H. (2006) Disturbance of cerebellar synaptic maturation in mutant mice lacking BSRPs, a novel brain-specific receptor-like protein family. FEBS, Lett., 580, 4057-4064. 
Miyazaki, T., Yamasaki, M., Takeuchi, T., Sakimura, K., Mishina, M. \& Watanabe, M. (2010) Ablation of glutamate receptor GluR $\delta 2$ in adult Purkinje cells causes multiple innervation of climbing fibers by inducing aberrant invasion to parallel fiber innervation territory. J. Neurosci., 30, 15196-15209.

Miyazaki T, Yamasaki M, Hashimoto K, Yamazaki M, Abe M, Usui H, Kano M, Sakimura K. \& Watanabe M. Cav2.1 in cerebellar Purkinje cells regulates competitive excitatory synaptic wiring, cell survival, and biochemical cerebellar compartment. in submission.

Morara, S., van der Want, J.J., de Weerd, H., Provini, L. \& Rosina, A. (2001) Ultrastructural analysis of climbing fiber-Purkinje cell synaptogenesis in the rat cerebellum. Neuroscience, 108, 655-671.

Nakamura, M., Sato, K., Fukaya, M., Araishi, K., Aiba, A., Kano, M. \& Watanabe, M. (2004) Signaling complex formation of phospholipase C $\beta 4$ with mGluR1 $\alpha$ and IP3R1 at the perisynapse and endoplasmic reticulum in the mouse brain. Eur. J. Neurosci., 20, 2929-2944.

Napper, R.M., \& Harvey, R.J. (1988). Number of parallel fiber synapses on an individual Purkinje cell in the cerebellum of the rat. J. Comp. Neurol., 274, 168-177.

Nomura, S., Fukaya, M., Tsujioka, T., Wu, D. \& Watanabe, M. (2007) Phospholipase 
$\mathrm{C} \beta 3$ is distributed in both somatodendritic and axonal compartments and localized around perisynapse and smooth endoplasmic reticulum in mouse Purkinje cell subsets. Eur. J. Neurosci., 25, 659-672.

Offermanns, S., Hashimoto, K., Watanabe, M., Sun, W., Kurihara, H., Thompson, R.F., Inoue, Y., Kano, M. \& Simon, M.I. (1997) Impaired motor coordination and persistent multiple climbing fiber innervation of cerebellar Purkinje cells in mice lacking Gaq. Proc. Natl. Acad. Sci. USA, 94, 14089-14094.

Ohtsuki, G. \& Hirano, T. (2008) Bidirectional plasticity at developing climbing fiber-Purkinje neuron synapses. Eur. J. Neurosci., 28, 2393-2400.

Palay, S.L. \& Chan-Palay, V. (1974) Cerebellar Cortex. Springer-Verlag, New York.

Piochon C, Irinopoulou T, Brusciano D, Bailly Y, Mariani J, Levenes C (2007) NMDA receptor contribution to the climbing fiber response in the adult mouse Purkinje cell. J.Neurosci., 27:10797-10809.

Rabacchi, S., Bailly, Y., Delhaye-Bouchaud, N. \& Mariani. J. (1992) Involvement of the $\mathrm{N}$-methyl D-aspartate (NMDA) receptor in synapse elimination during cerebellar development. Science, 256, 1823-1825.

Ramon y Cajal, S. (1911) Histologie du systeme nerveux de l'homme et des vertebres. vol. II. Maloine, Paris. 
Renzi M, Farrant M, Cull-Candy SG (2007) Climbing-fibre activation of NMDA receptors in Purkinje cells of adult mice. J. Physiol. (London), 585: 91-101.

Ribar, T.J., Rodriguiz, R.M., Khiroug, L., Wetsel, W.C., Augustine, G.J. \& Means, A.R. (2000) Cerebellar defects in $\mathrm{Ca}^{2+} /$ calmodulin kinase IV-deficient mice. J. Neurosci., 20, RC107.

Roth, A \& Hausser, M. (2001) Compartmental models of rat cerebellar Purkinje cells based on simultaneous somatic and dendritic patch-clamp recordings. J. Physiol., 535, $445-472$.

Saito, N., Kikkawa, U., Nishizuka, Y. \& Tanaka, C. (1988) Distribution of protein kinase C-like immunoreactive neurons in rat brain. J. Neurosci., 8, 369-382.

Sanes, J.R. \& Lichtman, J.W. (1999) Development of the vertebrate neuromuscular junction Annu Rev Neurosci 22, 389-442.

Scelfo, B. \& Strata, P. (2005) Correlation between multiple climbing fibre regression and parallel fibre response development in the postnatal mouse cerebellum. Eur. J. Neurosci., 21, 971-978.

Sherrard, R.M., Dixon, K.J., Bakouche, J., Rodger, J., Lemaigre-Dubreuil, Y. \& Mariani, J. (2009) Differential expression of TrkB isoforms switches climbing fiber-Purkinje cell 
synaptogenesis to selective synapse elimination. Dev. Neurobiol., 69, 647-662.

Shigemoto, R., Nakanishi, S. \& Mizuno, N. (1992) Distribution of the mRNA for a metabotropic glutamate receptor (mGluR1) in the central nervous system: an in situ hybridization study in adult and developing rat. J. Comp. Neurol., 322,121-135.

Slemmon, J.R., Blacher, R., Danho, W., Hempstead, J.L. \& Morgan, J.I. (1984) Isolation and sequencing of two cerebellum-specific peptides. Proc. Natl. Acad. Sci. USA, 81, 6866-6870.

Song, J., Misgeld, T., Kang, H., Knecht, S., Lu, J., Cao, Y., Cotman, S., Bishop, D. \& Lichtman, J. (2008) Lysosomal activity associated with developmental axon pruning. $J$. Neurosci., 28, 8993-9001.

Stea, A., Tomlinson, W.J., Soong, T.W., Bourinet, E., Dubel, S.J., Vincent, S.R. \& Snutch, T.P. (1994) Localization and functional properties of a rat brain $\alpha 1 \mathrm{~A}$ calcium channel reflect similarities to neuronal Q- and P-type channels. Proc. Natl. Acad. Sci. USA, 91, 10576-10580.

Sugihara, I. (2005) Microzonal projection and climbing fiber remodeling in single olivocerebellar axons of newborn rats at postnatal days 4-7. J. Comp. Neurol., 487, 93-106. 
Sugihara, I., Bailly, Y. \& Mariani, J. (2000) Olivocerebellar climbing fibers in the granuloprival cerebellum: morphological study of individual axonal projections in the X-irradiated rat. J. Neurosci., 20, 3745-3760.

Sugihara, I., Wu, H.S. \& Shinoda, Y. (2001) The entire trajectories of single olivocerebellar axons in the cerebellar cortex and their contribution to Cerebellar compartmentalization. J. Neurosci., 21, 7715-7723.

Takagishi, Y., Hashimoto, K., Kayahara, T., Watanabe, M., Otsuka, H., Mizoguchi, A., Kano, M. \& Murata, Y. (2007) Diminished climbing fiber innervation of Purkinje cells in the cerebellum of myosin Va mutant mice and rats. Dev. Neurobiol., 67, 909-923.

Takayama, C., Nakagawa, S., Watanabe, M., Mishina, M. \& Inoue, Y. (1995) Light- and electron-microscopic localization of the glutamate receptor channel $\delta 2$ subunit in the mouse Purkinje cell. Neurosci, Lett., 188, 89-92.

Takechi, H., Eilers, J. \& Konnerth, A. (1998) A new class of synaptic response involving calcium release in dendritic spines. Nature, 396, 757-760.

Takeuchi, T., Miyazaki, T., Watanabe, M., Mori, H., Sakimura, K. \& Mishina, M. (2005) Control of synaptic connection by glutamate receptor $\delta 2$ in the adult cerebellum. $J$. Neurosci., 25, 2146-2156.

Tanaka, J., Nakagawa, S., Yamasaki, M., Fukaya, M., Iwanaga, T., Sakimura, K., Kano, 
M., Simon, M.I., Inoue, Y. \& Watanabe, M. (2000) Gq protein $\alpha$ subunits Gaq and Go11 are localized at postsynaptic extra-junctional membrane of cerebellar Purkinje cells and hippocampal pyramidal cells. Eur. J. Neurosci., 12, 781-792.

Torashima, T., Iizuka, A., Horiuchi, H., Mitsumura, K., Yamasaki, M., Koyama, C., Takayama, K., Iino, M., Watanabe, M. \& Hirai, H. (2009) Rescue of abnormal phenotypes in $\delta 2$ glutamate receptor-deficient mice by the extracellular N-terminal and intracellular C-terminal domains of the $\delta 2$ glutamate receptor. Eur. J. Neurosci., 30, $355-365$.

Uemura, T., Lee, S.J., Yasumura, M., Takeuchi, T., Yoshida, T., Ra, M., Taguchi, R., Sakimura, K. \& Mishina, M. (2010) Trans-synaptic interaction of GluR $\delta 2$ and Neurexin through Cbln1 mediates synapse formation in the cerebellum. Cell, 141, 1068-1079.

Urade, Y., Oberdick, J., Molinar-Rode, R. \& Morgan, J.I. (1991) Precerebellin is a cerebellum-specific protein with similarity to the globular domain of complement $\mathrm{Clq}$ B chain. Proc. Natl. Acad. Sci. USA, 88, 1069-1073.

Watanabe, M. (2008) Molecular mechanisms governing competitive synaptic wiring in cerebellar Purkinje cells. Tohoku J. Exp. Med., 214, 175-190.

Watanabe, F., Miyazaki, T., Takeuchi, T., Fukaya, M., Nomura, T,. Noguchi, S., Mori, H., Sakimura, K., Watanabe, M. \& Mishina, M. (2008) Effects of FAK ablation on cerebellar foliation, Bergmann glia positioning and climbing fiber territory on Purkinje 
cells. Eur. J. Neurosci., 27, 836-854.

Watanabe, M., Nakamura, M., Sato, K., Kano, M., Simon, M.I. \& Inoue, Y. (1998) Patterns of expression for the mRNA corresponding to the four isoforms of phospholipase C $\beta$ in mouse brain. Eur. J. Neurosci., 10, 2016-2025.

Watase, K., Hashimoto, K., Kano, M., Yamada, K., Watanabe, M., Inoue, Y., Okuyama, S., Sakagawa, T., Ogawa, S., Kawashima, N., Hori, S., Takimoto, M., Wada, K. \& Tanaka, K. (1998) Motor discoordination and increased susceptibility to cerebellar injury in GLAST mutant mice. Eur. J. Neurosci., 10, 976-988.

Woodward, D.J. Hoffer, B.J., Siggins, G.R. \& Bloom, F.E. (1971) The ontogenetic development of synaptic junctions, synaptic activation and responsiveness to neurotransmitter substances in rat cerebellar purkinje cells. Brain Res., 34, 73-97.

Woodward, D.J., Hoffer, B.J. \& Altman, J. (1974) Physiological and pharmacological properties of Purkinje cells in rat cerebellum degranulated by postnatal x-irradiation. $J$. Neurobiol., 5, 283-304.

Yamada, K., Fukaya, M., Shimizu, H., Sakimura, K. \& Watanabe, M. (2001) NMDA receptor subunits GluR $\varepsilon 1$, GluR $\varepsilon 3$ and GluR $\zeta 1$ are enriched at the mossy fibre-granule cell synapse in the adult mouse cerebellum. Eur. J. Neurosci., 13, 2025-2036.

Yamasaki, M., Miyazaki, T., Azechi, H., Abe, M., Natsume, R., Hagiwara, T., Aiba, A., 
Mishina, M., Sakimura, K. \& Watanabe, M (2011) Glutamate receptor GluR $\delta 2$ is essential for input pathway-dependent regulation of synaptic AMPAR contents in cerebellar Purkinje cells. J. Neurosci., 31, 3362-3374, 2011. 


\section{Figure Legends}

Fig. 1. Postnatal development showing CF translocation to growing $\mathrm{PC}$ dendrites in C57BL/6 mice. A, B. Double immunofluorescence for VGluT2 (CF terminal marker, red) and calbindin (PC marker, green) at P3 (A) and P5 (B). At these stages, VGluT2-labeled CF terminals are mainly associated with calbindin-labeled PC processes (arrows). At P5, CF terminals take up more perisomatic position than at P3, and some terminals start to form clusters (arrowheads) around PC somata (asterisks). $C-G$. Fluorescent labeling for anterograde tracer biotinylated dextran amine (BDA, red) and calbindin (green) at P7 (C), P9 (D), P12 (E), P15 (F), and P20 (G). Pericellular nests are developed at P7 and P9 (pericellular nest stage). Then, perisomatic CF innervation is shifted to the apical side of PC somata at P12 (capuchon stage), and mostly to dendrites at P15 and P20 (dendritic stage). Note progressive dendritic translocation from P9 to P20. H, I. Developmental changes in the mean CF reach $(\mathrm{H})$ and its relative height in the molecular layer (I). Values are mean \pm S.D. for 10 to 12 CFs labeled with BDA from 3 mice at each age. CF reach was measured from the apical pole of PC somata to the tips of tracer-labeled CFs. $J$. The density of somatic spines forming $\mathrm{CF}$ synapses per $1 \mu \mathrm{m}$ of $\mathrm{CF}$ height. Values are mean \pm S.D. $K$. The composition of perisomatic CF synapses innervated by a single main BDA-labeled/VGluT2-labeled CF (yellow) and other BDA-unlabeled/VGluT2-labeled CFs (green). $L-N$. CF wiring reconstructed from serial electron microscopy at P9 (L), P12 (M), and P15 (N). Yellow lines and circles on the right side of each PC represent BDA-labeled/VGluT2-labeled single main CF, while green circles on the left side represent BDA-unlabeled/VGluT2-labeled weaker CFs. At P9 and P12, a single main CF translocates to dendrites, while keeping its perisomatic synapses together with those 
by weaker CFs. Most of perisomatic CF synapses are eliminated at P15. Figure $1 \mathrm{~A}$ and 1B are kindly provided by Dr. R. Ichikawa in Sapporo Medical University School of Medicine. Figure 1C-N is modified from Hashimoto et al, Neuron, 63:106-118, 2009. Scale bars, $20 \mu \mathrm{m}$.

Fig. 2. Developmental switching in perisomatic PC innervation from CFs to basket cell fibers in C57BL/6 mice. A-E. Triple fluorescent labeling for inhibitory terminals with vesicular inhibitory amino acid transporter (VIAAT) antibody (green, A1-E1), CFs with anterograde tracer BDA (red, A2-E2), and PCs with calbindin antibody (blue, both panels). Asterisks indicate PC somata. Double and single arrowheads indicate the tip or trajectory of CF projection, respectively. Large arrowheads in $E$ indicate the pinceau formation surrounding the axon initial segment of PCs. F. The density of the total perisomatic synapses. The density is expressed as the number per $100 \mu \mathrm{m}^{2}$ of somatic surface area. $G$. The composition of four types of perisomatic synapses; basket fiber-PC soma synapse (BF-soma. light green), basket fiber-PC spine synapse (BF-spine, green), and CF-PC spine synapse (CF-spine, red), and other somatic synapse (blue). $H$. Summary illustrations on developmental switching of perisomatic innervation and receptor phenotype in PCs. At $\mathrm{P} 7$ and $\mathrm{P} 9$, the predominance of $\mathrm{CF}$-spine (CF-Sp) synapses corresponds to the pericellular nest stage of $\mathrm{CF}$ innervation. At P12, perisomatic CF-spine synapses are displaced to the apical somatic portion and shaft dendrites (the capuchon stage), whereas BF-spine synapses (BF-Sp) and BF-soma synapses (BF-Sm) increase reciprocally. At this stage, fragmental GluA2 and $\mathrm{GABA}_{\mathrm{A}} \mathrm{R} \alpha 1$ clusters co-exist under the same BF terminals, particularly, at basal somatic portion. At P15, the major perisomatic synapses are BF synapses composed of 
BF-spine and BF-soma synapses, and most CF-spine synapses are eliminated from PC somata (the dendritic stage). At P20, most perisomatic synapses become BF-soma synapses and the pinceau is established, thus attaining the adult type of innervation. Free spines surrounded by BFs (FS-BF) or BG (FS-BG) also appear transiently during the period of CF-to-BF switchover. Modified from Ichikawa et al. (in submission). Scale bars, $20 \mu \mathrm{m}$.

Fig. 3. Four developmental phases in the process from multiple innervation to mono-innervation of PCs by CFs. Until P3, synaptic strengths of multiply-innervating CFs are relatively uniform. From P3 to P7, one CF is selectively strengthened, thus being termed the phase of "functional differentiation." From P9 on, the strongest CF undergoes dendritic translocation (the phase of "CF translocation"). On the other hand, the average number of CFs per PC shows no significant reduction from P3 to P6 (>5 $\mathrm{CFs}$ ), and progressively decreases from P6. Electrophysiological analysis on GluR $\delta 2$ KO mice demonstrates the "early phase of CF synapse elimination" during P7-P11, which is independent of PF-PC synapse formation, and the "late phase of CF synapse elimination" during P12-P17, which requires normal PF-PC synapse formation.

Fig. 4. Electrophysiological evidence for functional differentiation, synapse elimination and translocation of CFs. A. CF-EPSCs recorded in a PC at P3 (upper) or at P12 (lower). Two to three traces are superimposed at each threshold stimulus intensity. Holding voltage $\left(\mathrm{V}_{\mathrm{h}}\right)$ was $-80 \mathrm{mV}$ for $\mathrm{P} 3$ and $-20 \mathrm{mV}$ for P12. B. Developmental changes in the Disparity Ratio. The amplitudes of individual CF-EPSCs in a given multiply-innervated PC were measured at the same $V_{h}$ and they were numbered in the order of their 
amplitudes $\left(A_{1}, A_{2}, \ldots, A_{i}, \ldots, A_{N}, N \geq 2, N\right.$ is the number of $C F s$ innervating a given PC. $A_{i}$ is the EPSC amplitude for the $C_{i}$. $A_{N}$ represents the EPSC amplitude for the strongest $\mathrm{CF}$ ). Disparity Ratio was calculated by the following formula;

Disparity Ratio $=\frac{\sum_{i=1}^{N-1} \frac{A_{i}}{A_{N}}}{N-1} \quad(\mathrm{~N} \geq 2)$

Data for P9-P11 and those for P12-P14 are pooled and indicated with filled triangles. Data for P15 to P21 are pooled and indicated with filled boxes. $C$. Postnatal changes in the averaged number of CFs innervating each PC in C57BL/6 mice (filled blue), control mice for GluD2 KO mice (open black) and GluD2 KO mice (filled black). The values of GluD2 knockout mice are significantly larger than control at P12, P13 and P14 (**, $\mathrm{p}<0.01$, Mann-Whitney U-test). $D, E$. Average cumulative histograms for the $10-90 \%$ rise times of qEPSCs arising from CF-mono (green), CF-multi-S (pink) and CF-multi-W (blue) at P7-P8 $(D)$ and P11-P14 (E). F. Postnatal changes in the total amplitudes of CF-EPSCs (at $\mathrm{V}_{\mathrm{h}}=-20 \mathrm{mV}$ ) elicited in each PC in control (open) and PC-Cav2.1 KO (gray) mice. $G, H$. Postnatal changes in the fractions of the largest (blue), second (pink), third (green), and fourth (violet) EPSC amplitudes relative to the total CF-EPSC amplitude in control $(G)$ and PC-Cav2.1 KO $(H)$ PCs. Values are expressed as mean \pm sem. $A$ and $B$ are modified from Hashimoto and Kano, Neuron, 38, 785-796, 2003. $C$ is modified from Hashimoto et al., Neuroscience, 162, 601-611.2009b. $D$ and $E$ are modified from Hashimoto et al., Neuron, 63:106-118, 2009a. F, G and H are modified from Hashimoto et al. Proc. Natl. Acad. Sci. USA. 108, 9987-9992, 2011.

Fig. 5. Cellular and molecular mechanisms underlying the early and late phase of CF synapse elimination in early postnatal development. Top, Early phase of CF synapse 
elimination. $\mathrm{CF}$ activities leading to $\mathrm{Ca}^{2+}$ influx through the P/Q-type VDCC will assign the resource (?) to respective CF synapses in an activity-dependent manner. This promotes functional differentiation and fuels homosynaptic competition among multiply-innervating $\mathrm{CF}$ inputs. As a result, the strongest $\mathrm{CF}$ is only permitted to translocate to dendrites, which then fuels heterosynaptic competition with PF inputs. Other weaker CFs remain on the soma, until their perisomatic synapses are massively eliminated. Bottom, Late phase of CF synapse elimination. In the late phase of CF synapse elimination, PF-PC synapses play two important roles with each being conducted by different molecular mechanisms. First, trans-synaptic interaction of presynaptic neurexin and postsynaptic GluR $\delta 2$ via Cbln1 consolidate structural connectivity of PF-PC synapses at distal dendrites, which eventually restrict CF innervation to proximal dendrites. Second, neural activities transmitted along the mossy fiber-to-GC/PF-to-PC pathway activate the mGluR1-to-PKC $\gamma$ signaling cascade in PCs. In the downstream of this cascade, certain signals (?) are produced to drive non-selective elimination of perisomatic CF synapses. TrkB, myosin Va, BSRP and GLAST are also involved in the late phase of CF synapse elimination. Modified from Kano et al, Phil. Trans. R. Soc. B 363, 2173-2186, 2008.

Fig. 6. Summary diagram illustrating molecular mechanisms for competitive synaptic wiring in PCs. In wild-type animals, a single main CF (black beaded fiber) monopolizes the proximal domain of PC dendrites (purple) and establishes hundreds of glutamatergic synapses, while numerous PFs innervate the distal dendritic domain (green) and form $1: 1$, or $1: 2$, contact ratio with PC spines (middle). Note opposite shift of CF and PF territories between GluR $\delta 2 / C b \ln 1 \mathrm{KO}$ (left) and $\mathrm{Ca} 22.1 \mathrm{KO}$ (right) mice. When the 
territories are shifted to either direction, innervation of surplus CFs (gray beaded fibers) is permitted to cause multiple CF innervation at distinct dendritic domains, and the intermediate domain of PC dendrites (light blue), which innervated by both CFs and PFs, expands. Furthermore, in $\mathrm{Cav}_{\mathrm{v}} 2.1 \mathrm{KO}$, a fraction of PF terminals are enlarged and make contact with several PC spines (arrowheads). Although synaptic wiring in mGluR1 KO mice is not illustrated in this diagram, the mGluR1 signaling cascade mediates PF synapse activities to lead to the pruning of surplus CFs. Armed with all these mechanisms, CF and PF territories are sharply bordered and aberrant innervation by surplus CFs is prevented in wild-type animals (middle). Modified from Watanabe, Tohoku Journal of Experimental Medicine 214:175-190, 2008. 


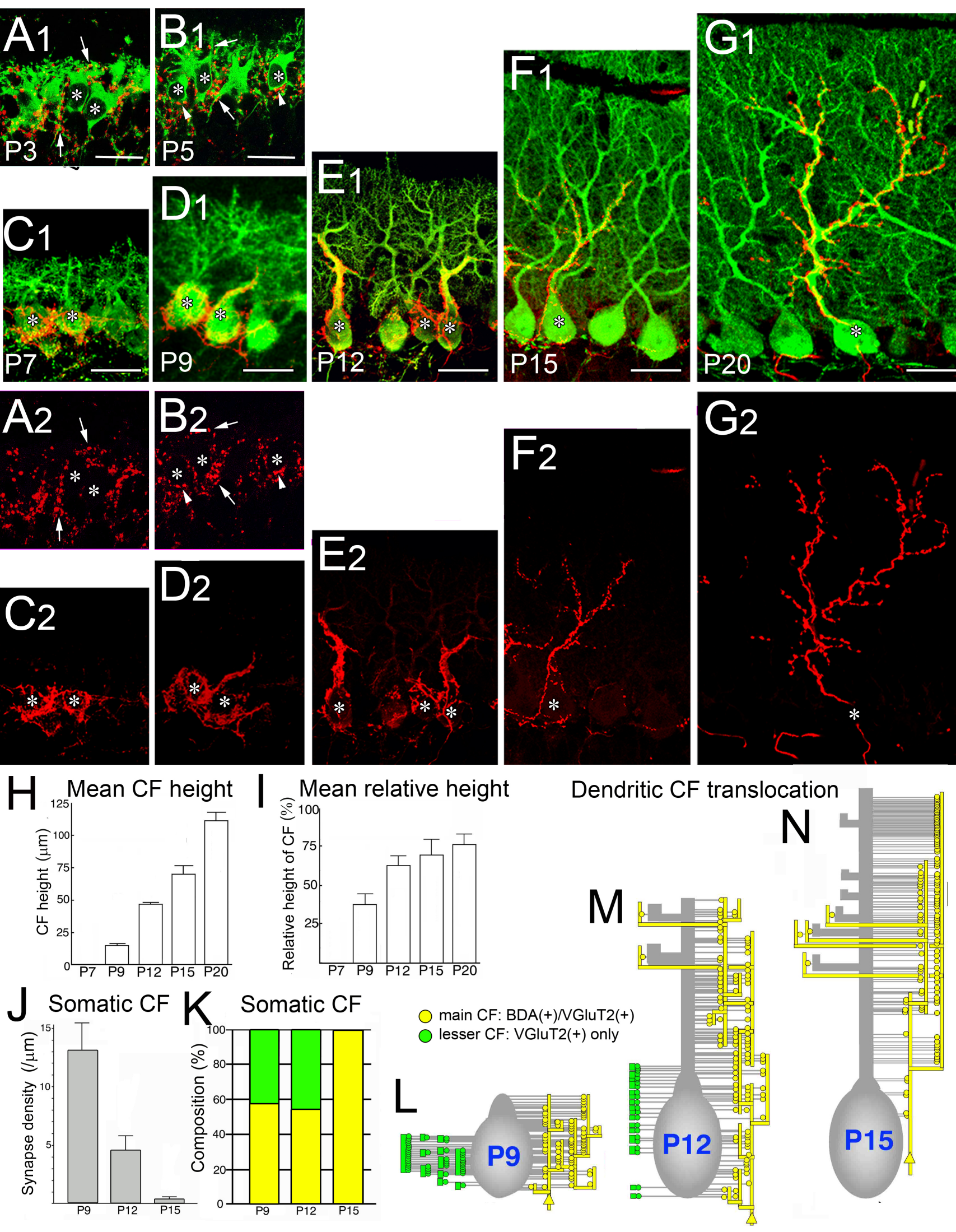




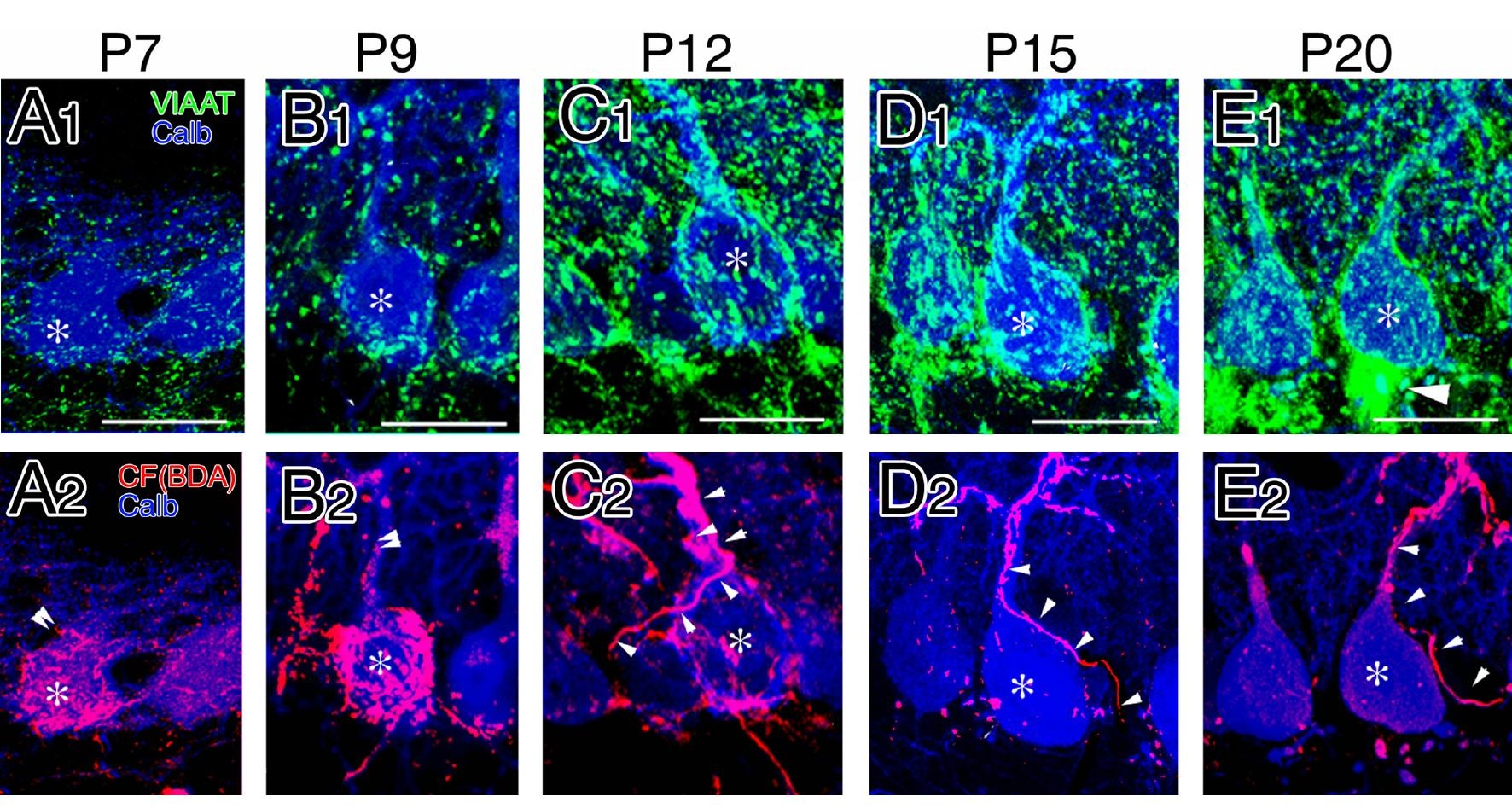

\section{$\mathrm{F}$}

Density of total perisomatic synapses

$\mathrm{P} 7$
$\mathrm{P}$
$\mathrm{P}$
$\mathrm{P}$
G Composision of perisomatic PC synapses

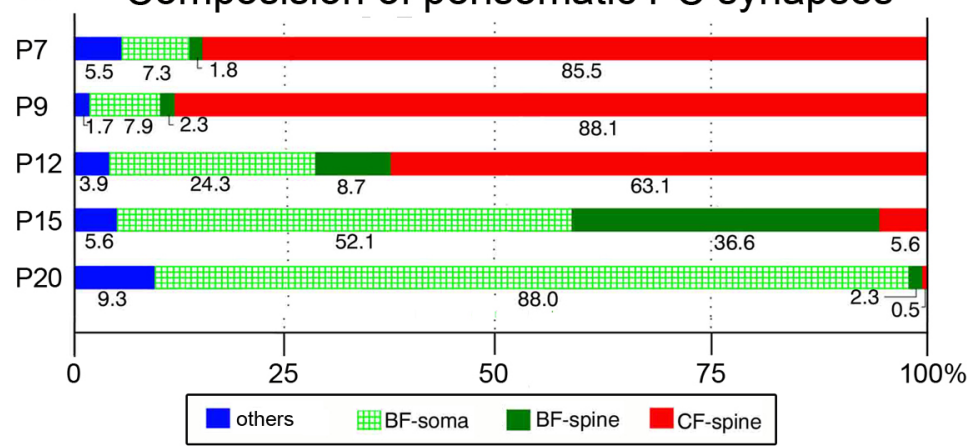

Switching of presynaptic element and postsynaptic receptor
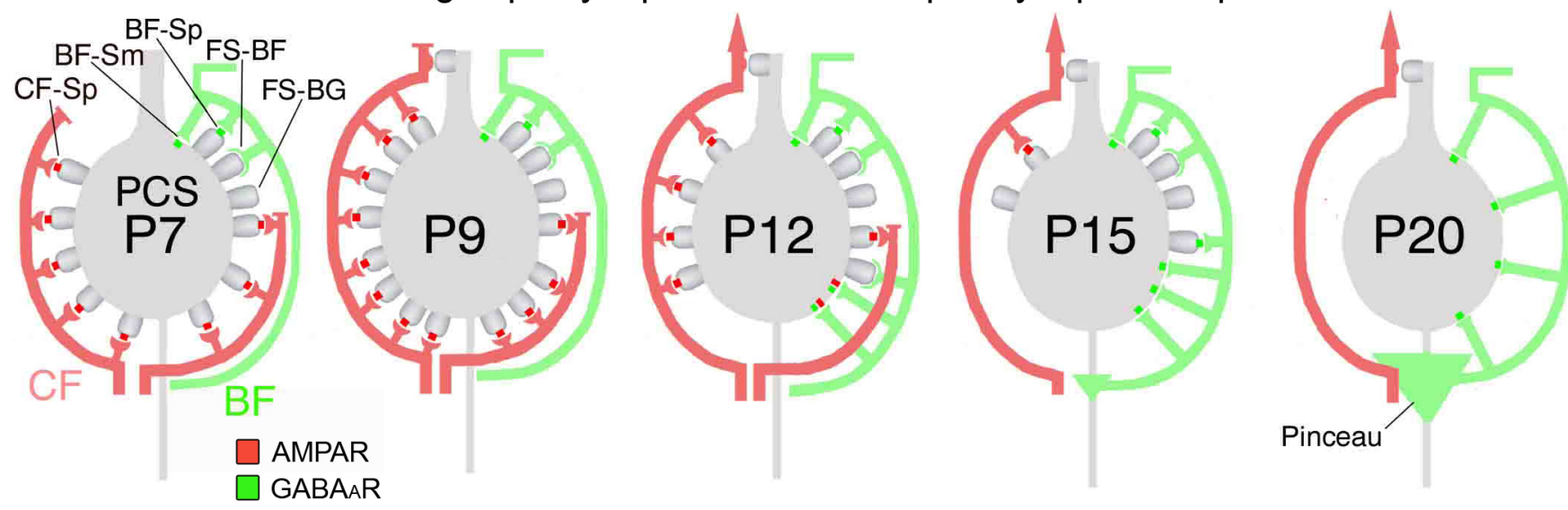


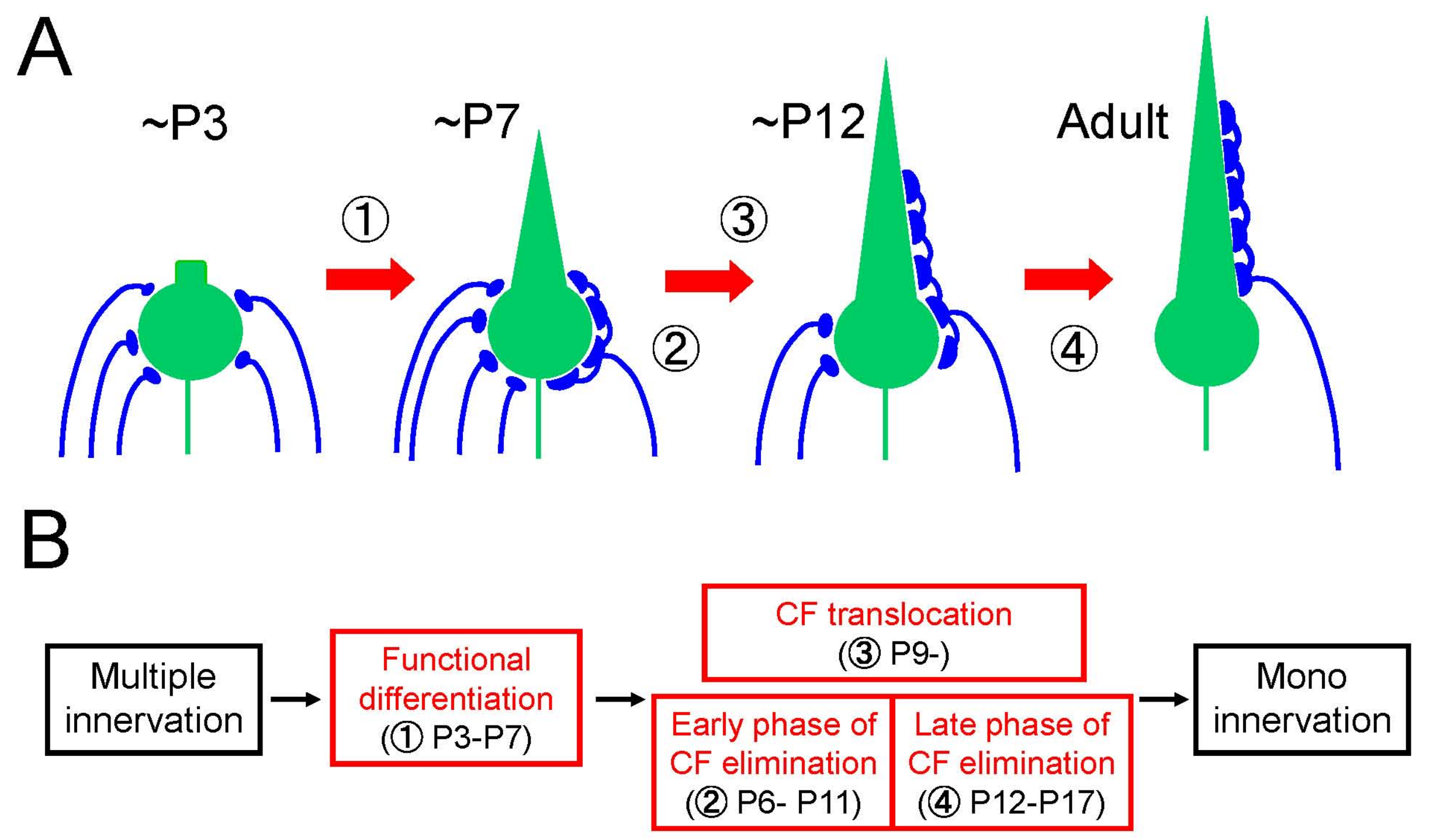




\section{Early Phase}

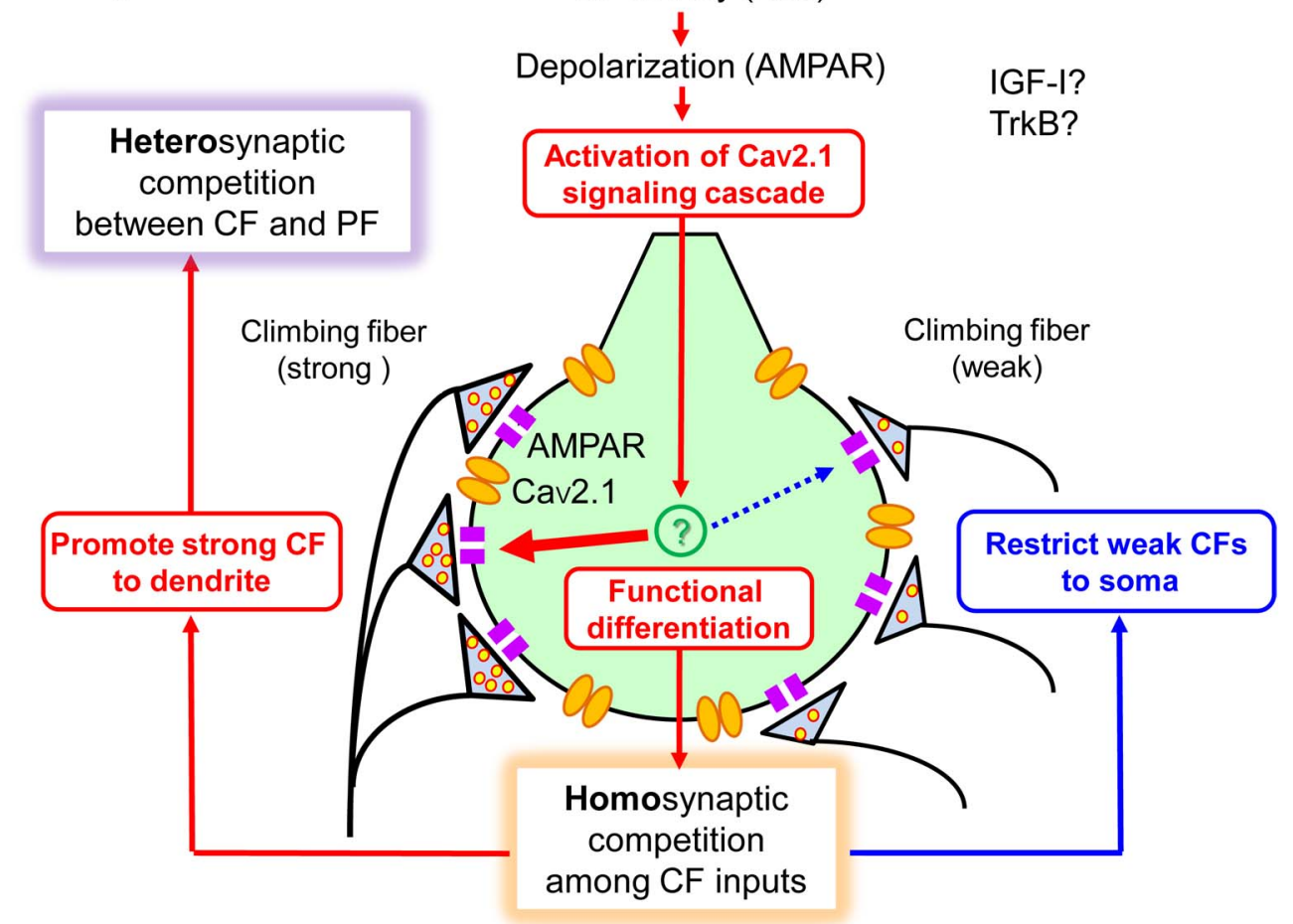

\section{Late Phase}

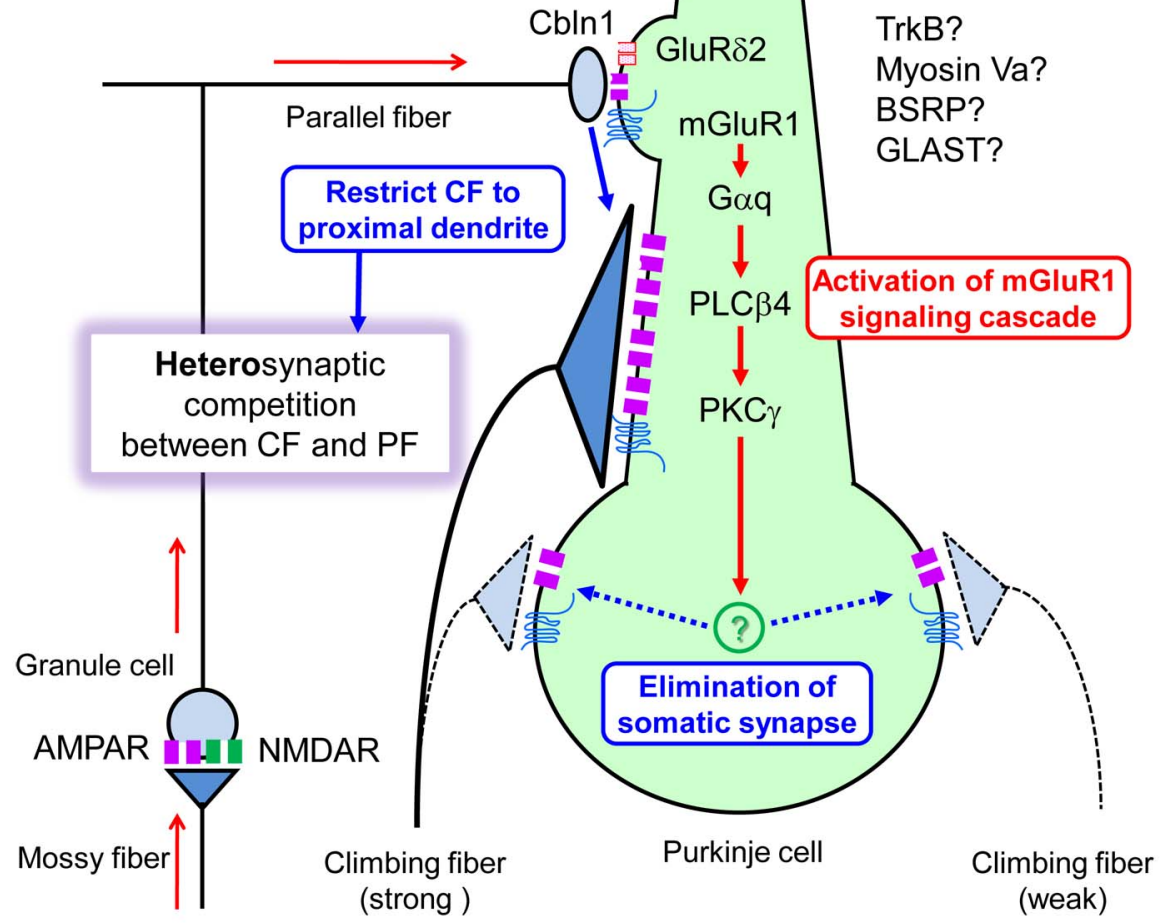




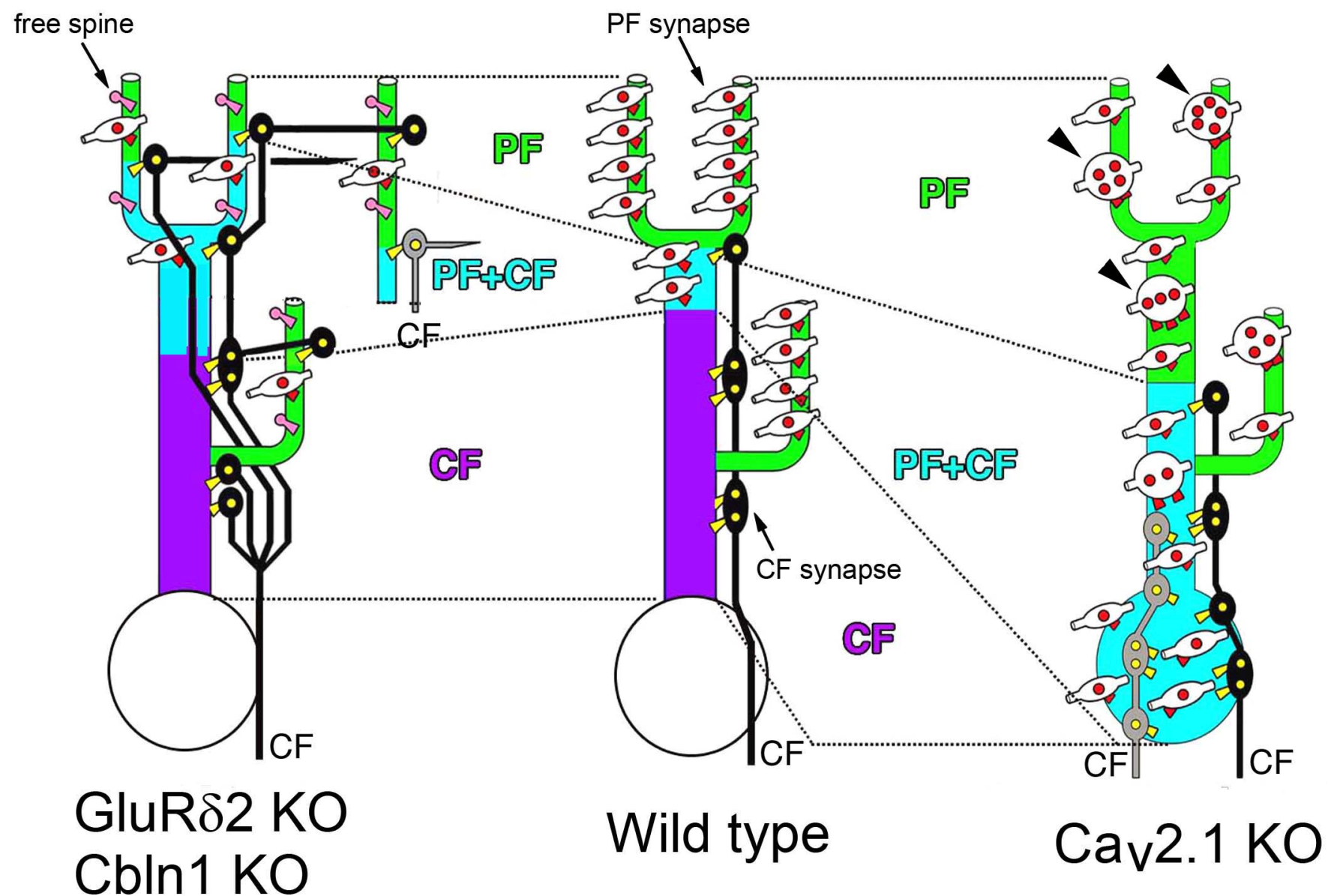

